\title{
Convective Snowbands Downstream of the Rocky Mountains in an Environment with Conditional, Dry Symmetric, and Inertial Instabilities
}

\author{
RUSS S. SCHUMACHER \\ Department of Atmospheric Science, Colorado State University, Fort Collins, and National Center for Atmospheric \\ Research,* Boulder, Colorado, and Department of Atmospheric Sciences, Texas A\&M University, College Station, Texas \\ DAVID M. SCHULTZ \\ Division of Atmospheric Sciences, Department of Physics, University of Helsinki, and Finnish Meteorological Institute, \\ Helsinki, Finland, and Centre for Atmospheric Science, School of Earth, Atmospheric and Environmental Sciences, \\ University of Manchester, Manchester, United Kingdom \\ JOHN A. KNOX \\ Department of Geography, The University of Georgia, Athens, Georgia
}

(Manuscript received 6 January 2010, in final form 7 May 2010)

\begin{abstract}
Convective snowbands moved slowly over Wyoming and northern Colorado on 16-17 February 2007 and produced up to $71 \mathrm{~mm}$ ( $2.8 \mathrm{in}$.) of snow that was unpredicted by operational numerical weather prediction models and human forecasters. The northwest-southeast-oriented bands lasted for over $6 \mathrm{~h}$, comprising both a single major band (more than $30 \mathrm{~km}$ wide) and multiple minor bands (about $10 \mathrm{~km}$ wide). The convective bands initiated within the ascending branch of a secondary circulation associated with both near-surface and elevated frontogenesis, but the bands remained nearly stationary while the near-surface frontogenesis moved quickly equatorward. The bands occurred downstream of complex terrain on the anticyclonic-shear side of a midlevel jet streak, where conditional, dry symmetric (negative potential vorticity), and inertial (negative absolute vorticity) instabilities were present.

To determine the mechanisms responsible for the development and organization of these bands, simulations using a convection-permitting numerical model are conducted. In contrast to the operational models, these simulations are able to produce convective bands in the same area and at about the same time as that observed. The simulated bands occurred in an environment with a nearly well-mixed, baroclinic boundary layer, positive convective available potential energy, and widespread negative potential vorticity. Individual bands initiated on the low-momentum side of vorticity banners downstream of mountains, and in association with frontogenetical ascent along two baroclinic zones. In addition, ascent caused by both frontogenesis and banded moist convection produced additional narrow regions of negative vorticity by transporting lowmomentum air upward and creating strong horizontal gradients in wind speed. This event is similar to other observed instances of banded convection in the western United States on the anticyclonic-shear side of strong mid- and upper-tropospheric jets in environments lacking large-scale saturation. In contrast, these events differ from previously published banded precipitation events in the comma head of extratropical cyclones and downstream of mountains where large-scale saturation is present.
\end{abstract}

* The National Center for Atmospheric Research is sponsored by the National Science Foundation.

Corresponding author address: Russ S. Schumacher, Dept. of Atmospheric Sciences, 3150 TAMU, College Station, TX 778433150 .

E-mail: russ.schumacher@tamu.edu

\section{Introduction}

On 16-17 February 2007, northwest-southeast-oriented convective bands developed on the plains of Colorado, Wyoming, and Nebraska (Fig. 1). Around 1600 UTC (0900 LST; LST = UTC - 7 h), a convective band initiated along an equatorward-moving surface cold front in eastern Wyoming and the Nebraska Panhandle, producing 

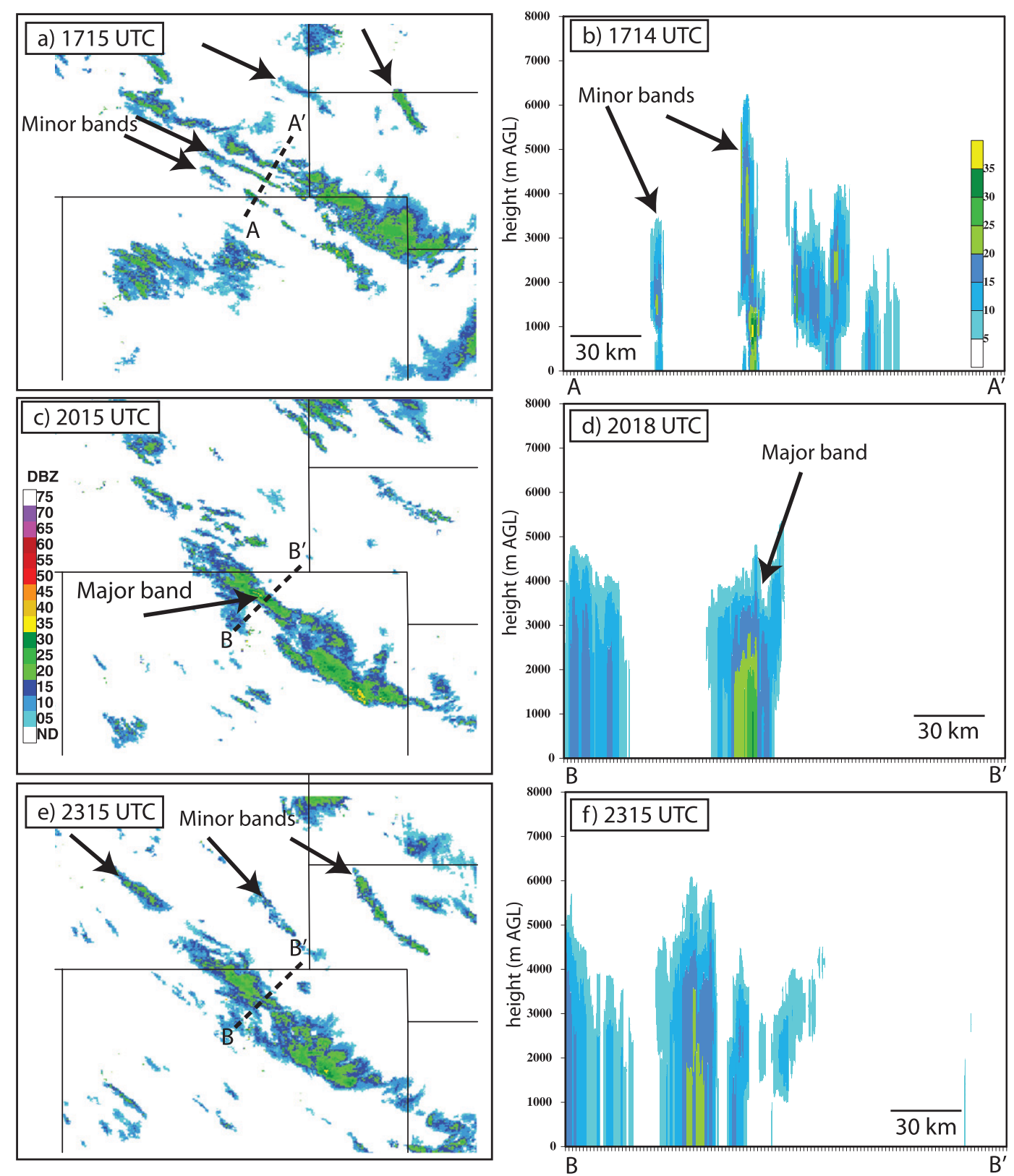

FIG. 1. Observed composite reflectivity (from the WSI NOWrad product) at (a) 1715, (c) 2015, and (e) 2315 UTC $16 \mathrm{Feb} 2007$, and vertical sections of the radar reflectivity factor from the Cheyenne radar at (b) 1714, (d) 2018, and (f) 2315 UTC 16 Feb 2007. The vertical section in (b) is taken along the dashed line $\mathrm{A}-\mathrm{A}^{\prime}$ shown in (a), and the sections in (d) and (f) are taken along the dashed line B-B' shown in (c) and (e). Locations of the major and minor bands discussed in the text are indicated by arrows. These times were selected because they best illustrate the differences between the major and minor bands.

lightning, small hail, and snow pellets in eastern Wyoming (not shown). By 1715 UTC, several new, narrow convective bands had also joined the original wider band (Figs. 1a and $1 \mathrm{~b}$ ). These narrow bands moved southward and consolidated, and by 2015 UTC, the primary convective band extended from the Colorado-Wyoming border southeastward onto the plains and the Colorado-Kansas border
(Fig. 1c). This primary band had a width of approximately $30 \mathrm{~km}$ (Figs. 1d and 1f) and a length of over $500 \mathrm{~km}$, and it remained nearly stationary (Figs. $1 \mathrm{c}$ and $1 \mathrm{e}$ ) until it began weakening after about 0200 UTC (not shown). Numerous other narrow convective bands were apparent in radar and satellite imagery in Wyoming, Colorado, South Dakota, and western Nebraska (Figs. 1 and 2), with widths of 


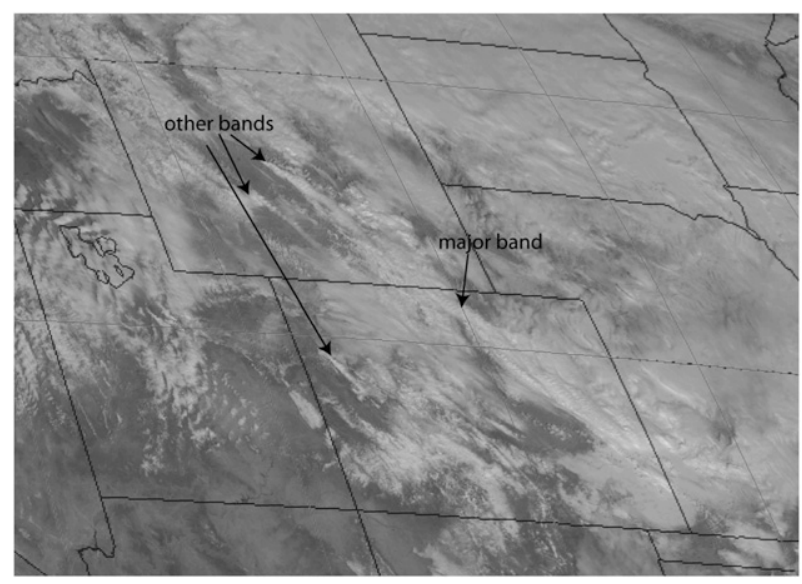

FIG. 2. Geostationary Operational Environmental Satellite-11 (GOES-11) visible satellite image at 2000 UTC 16 Feb 2007, with the locations of convective bands annotated.

5-20 km and lengths of 100-300 km. Throughout this manuscript, we call the primary band in southern Wyoming and northern Colorado the major band and the other narrower bands minor bands.

The major band produced over $4 \mathrm{~mm}$ (0.16 in.) of liquid equivalent precipitation in the $6 \mathrm{~h}$ ending 0000 UTC 17 February (Fig. 3a), which included up to $71 \mathrm{~mm}$ (2.8 in.) of snow in parts of Fort Collins (Fig. 4). At the Colorado State University Department of Atmospheric Science in western Fort Collins, the first author observed a transition from graupel to heavy snow and witnessed extremely icy roads throughout Fort Collins. Precipitation from the minor bands is also evident in eastern Wyoming and western Nebraska in Fig. 3a.

Meanwhile, severe downslope winds along the Front Range of the Rocky Mountains (Fig. 4) exceeded $45 \mathrm{~m} \mathrm{~s}^{-1}$ at the surface in some areas, with 24-h snowfall totals reaching $45.7 \mathrm{~cm}$ (18 in.) in the mountains. This combination of wind and snow produced low visibility and the threat of avalanches in the mountains, closing Interstate 70 for much of the Presidents' Day holiday weekend, which is typically one of the busiest weekends of the year for Colorado's ski resorts (The Denver Post, 18 February 2007).

Although the snow and wind in the mountains were well forecast by numerical weather prediction models and by human forecasters at the National Weather Service, the banded convection and snowfall on the plains in Wyoming, Colorado, and Nebraska was largely unpredicted by both models and humans. For example, the National Centers for Environmental Prediction's (NCEP) North American Mesoscale (NAM) operational model did not provide any indication that precipitation would fall over the plains of Wyoming, Colorado, and Nebraska (Fig. 3b). The NAM uses the Nonhydrostatic Mesoscale Model version of the Weather Research and Forecasting modeling system (WRF-NMM; Janjić et al. 2010).

Furthermore, the zone forecast issued at 1140 UTC from the National Weather Service office in Cheyenne, Wyoming, included a $20 \%$ chance of rain and snow for Cheyenne, and the forecast issued at 1141 UTC from the Denver-Boulder, Colorado, office for the Fort Collins a) Stage IV Observed 6-hr Precipitation

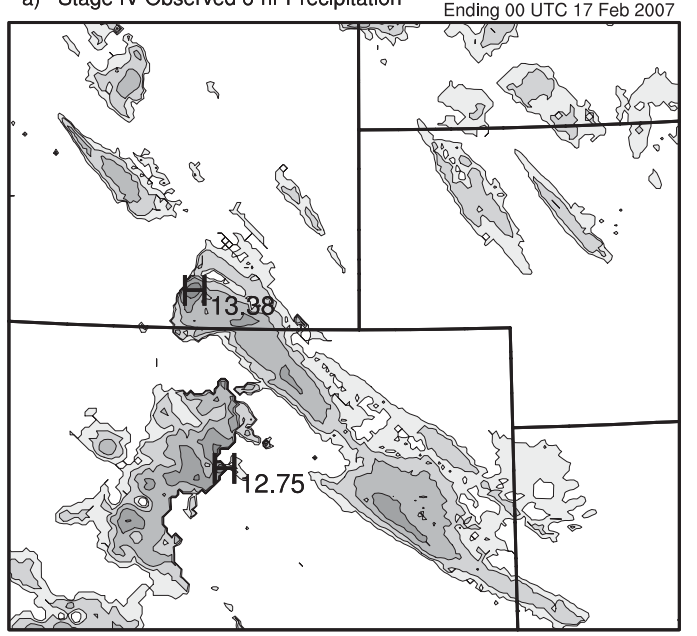

b) NAM Forecast 6-h precipitation

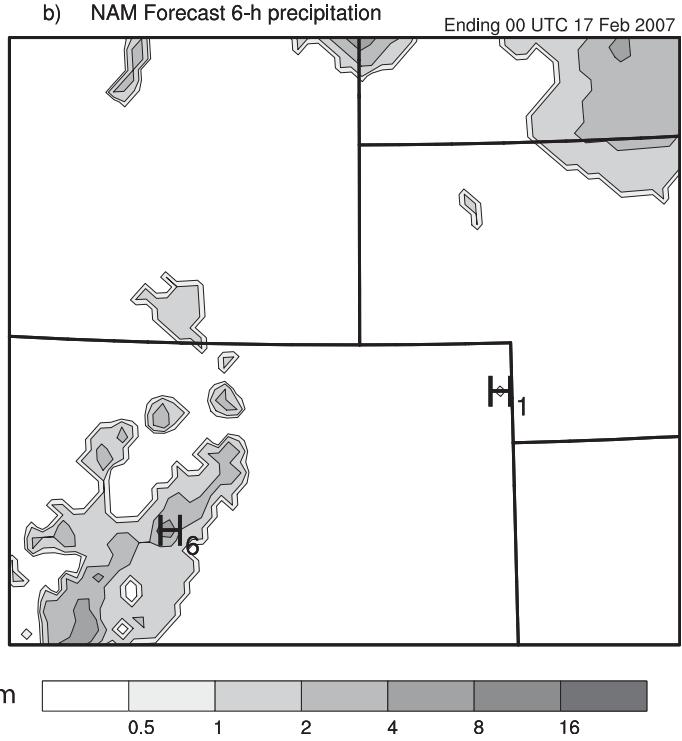

FIG. 3. Comparison of observed precipitation against an operational model forecast for the 6-h period between 1800 UTC 16 Feb and 0000 UTC 17 Feb 2007. (a) Observed precipitation (mm; liquid water equivalent) from the NCEP stage IV gridded analysis. (b) Precipitation forecast $(\mathrm{mm})$ from the NAM model initialized at 1200 UTC 16 Feb 2007. 


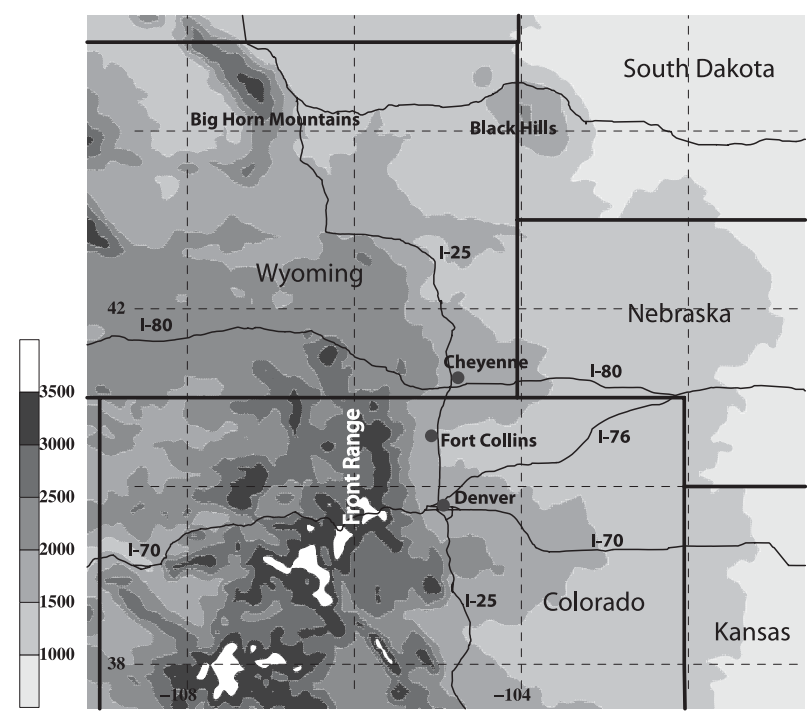

FIG. 4. Map showing the geography of the area of study. State borders are shown in thick black lines, interstate highways in thin black lines, and topography is shaded every $500 \mathrm{~m}$. Locations of cities, observing stations, and interstate highways discussed in the text are indicated.

area included a $20 \%$ chance of rain showers in the afternoon. As the convection began to develop, these probabilities were increased by the forecasters at these offices to a $40 \%$ chance of rain and snow for Cheyenne and a $30 \%$ chance of rain showers, snow showers, and thunderstorms in Fort Collins.

The purpose of this paper is to understand the processes that led to the development of convection and to its organization into bands of two sizes (major and minor). The remainder of this article is organized as follows. In section 2 of this article, observations of the 16-17 February 2007 snowband event are presented, highlighting the environmental conditions leading to the banded convection. Section 3 presents the results of high-resolution numerical simulations of the event. A discussion of our findings in relation to past work on banded convection and topographic circulations is presented in section 4 , and the article concludes with section 5 .

\section{Observations of the 16-17 February 2007 convective bands}

In this section, observations and analyses from several sources are used to investigate the atmospheric conditions prior to and during the development of the banded convection. Gridded surface and upper-air analyses, which are used as a proxy for observations, come from the NAM 6-hourly analyses, which have a horizontal grid spacing of $12 \mathrm{~km}$. Precipitation fields come from the NCEP stage IV multisensor product, which combines precipitation observations from rain gauges and radarestimated precipitation (Lin and Mitchell 2005) and is produced on a 4-km horizontal grid. Point values of precipitation come directly from rain gauge measurements, some of which were obtained from the Community Collaborative Rain, Hail, and Snow Network (CoCoRaHS; information online at http://www.cocorahs.org). Radar imagery comes from composites from individual radars in the NWS Weather Surveillance Radar-1988 Doppler (WSR-88D) network and reflects the highest value of reflectivity in the vertical column. These every-15-min composites, produced by the WSI Corporation, are called the National Operational Weather radar (NOWrad) product and have a horizontal grid spacing of $2 \mathrm{~km}$. The additional case studies shown in section 4 also include data from Rapid Update Cycle (RUC; Benjamin et al. 2004) hourly analyses and from individual WSR-88Ds.

\section{a. Overview}

About $6 \mathrm{~h}$ prior to the development of the convective snowbands (1200 UTC 16 February 2007), the upperlevel synoptic-scale flow consisted of a ridge over the eastern Pacific Ocean and a trough over the eastern United States (Fig. 5). Two 250-hPa jets with wind speeds exceeding $85 \mathrm{~m} \mathrm{~s}^{-1}$ were present: a primarily zonal jet across the southeastern United States and a northwesterly jet over the northwest United States (Fig. 5). The exit region of the northwesterly jet was located over northern Colorado, and was moving toward the southeast over Colorado during the day on 16 February (not shown). At the surface (Fig. 6a), a 995-hPa cyclone was centered over western North Dakota, with a warm front extending equatorward, and cold fronts extending westward and northwestward, from the low pressure center. West of the warm front, a lee trough was present along the Front Range of the Rockies in Colorado and New Mexico. At midlevels, there were strong winds (in excess of $30 \mathrm{~m} \mathrm{~s}^{-1}$ ) to the west of the developing cyclone (Fig. 6b), and there were regions of negative absolute vorticity [i.e., inertial instability; Knox (2003, p. 1007)] near and downstream of the mountains in Colorado and Wyoming. Another mesoscale region of inertial instability was located within strong anticyclonic shear and curvature on the poleward side of the cyclone in southern Saskatchewan, Canada (Fig. 6b).

During the day, the cyclone moved southeastward, with the warm front intensifying and moving eastward over the Great Plains by 1800 UTC, and the cold fronts moving equatorward (Fig. 6c). The midlevel jet also moved southeastward such that there continued to be strong anticyclonic shear and negative absolute vorticity poleward of the developing cyclone and near the high terrain (Fig. 6d). The inertially unstable region on the 


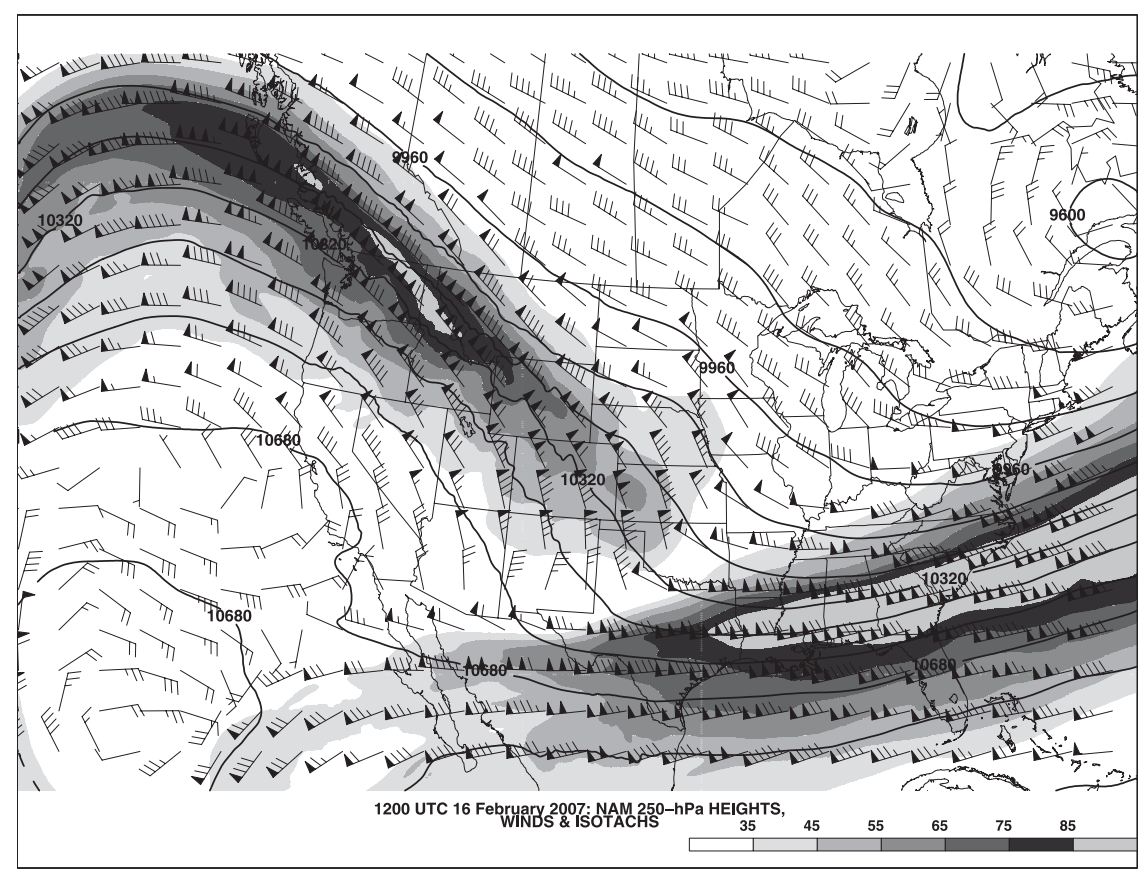

FIG. 5. Synoptic-scale analysis from the NAM of 250-hPa geopotential height (thick contours every $120 \mathrm{~m}$ ), winds (short barb represents $2.5 \mathrm{~m} \mathrm{~s}^{-1}$, long barb represents $5 \mathrm{~m} \mathrm{~s}^{-1}$, pennant represents $25 \mathrm{~m} \mathrm{~s}^{-1}$ ), and isotachs ( $\mathrm{m} \mathrm{s}^{-1}$, shaded) at 1200 UTC 16 Feb 2007.

poleward side of the cyclone was also still present in eastern Montana and southwestern South Dakota by 1800 UTC (Fig. 6d). The persistence of this mesoscale region of inertial instability contrasts with the statement by Holton $(2004$, p. 206) that the occurrence of inertial instability should be expected to immediately result in the release of that instability through lateral mixing.

\section{b. Ingredients for convection}

The environment in which the bands developed can be considered in terms of the three necessary ingredients for deep moist convection: lift, instability, and moisture (e.g., Johns and Doswell 1992). The primary low-level forcing for ascent was frontogenesis along a strengthening cold front, which moved equatorward across Colorado during the afternoon (Fig. 7). At 1800 UTC 16 February (Figs. 7a-c), a loosely organized area of precipitation associated with this baroclinic zone was located in northeast Colorado, and some narrow convective bands $\sim 10-\mathrm{km}$ wide were developing in southeast Wyoming and northwest Nebraska. The front and precipitation moved equatorward over the next $6 \mathrm{~h}$, rotating into a more northwest-southeast orientation (Figs. 7d-f). The narrow bands previously in southeast Wyoming had consolidated into the major band while new narrow bands (the minor bands) began to form in Nebraska and southeast Wyoming by 0000 UTC (Fig. 7d). The bands in Nebraska were associated with a second baroclinic zone and region of frontogenesis that was rotating around the southeastward-moving cyclone (Figs. 7d and 7e). After this equatorward movement and rotation, the major band became quasi-stationary, even as the low-level frontogenesis that was apparently the feature responsible for its organization passed equatorward (Figs. 1c, 1e, and 7e). By 0000 UTC 17 February, both the near-surface and elevated frontogenesis maxima were south of most of the major band, although the $700-\mathrm{hPa}$ frontogenesis maximum was collocated with the southeastern end of the major band (Figs. 7d-f).

The other two ingredients for the development of convection are instability and moisture. At 1800 UTC 16 February, a region of large lapse rates and relatively high water vapor mixing ratio (not shown) was located in northeast Colorado near the surface front. These features, along with further destabilization by daytime surface heating of about $5^{\circ} \mathrm{C}$, resulted in values of the most unstable convective available potential energy (MUCAPE) exceeding $500 \mathrm{~J} \mathrm{~kg}^{-1}$ (Fig. 7b) in some areas. Thus, conditionally unstable air was present in southern Wyoming, northeastern Colorado, and northern Nebraska during the time of convection initiation.

Although the NAM analysis at 1800 UTC showed MUCAPE values greater than $500 \mathrm{~J} \mathrm{~kg}^{-1}$, the 6-h NAM forecast valid at this time had substantially smaller values of MUCAPE (not shown). The underprediction of CAPE in the NAM forecast was associated with substantial 

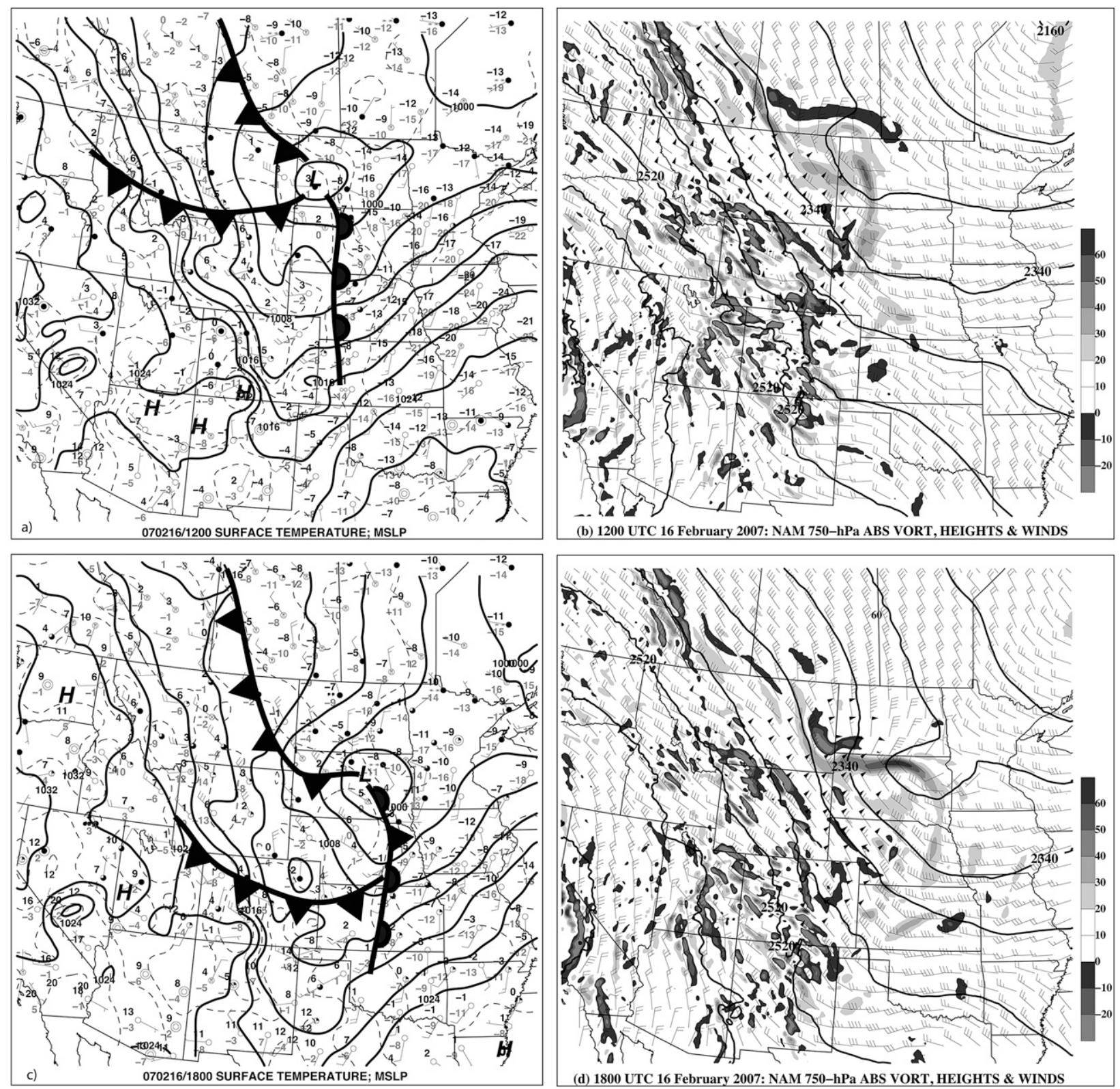

FIG. 6. (a),(c) Barnes objective surface analysis (Koch et al. 1983), showing pressure adjusted to sea level (solid contours every 4 hPa), surface temperature (gray dashed contours every $4^{\circ} \mathrm{C}$ ), and station model [conventional, with temperature $\left({ }^{\circ} \mathrm{C}\right)$ in black and dewpoint $\left({ }^{\circ} \mathrm{C}\right)$ in gray]. Fronts are shown in the conventional symbols; frontal locations were manually analyzed and are approximate. (b),(d) NAM analyses of 750-hPa geopotential height (thick contours every $60 \mathrm{~m}$ ), winds (short barb represents $2.5 \mathrm{~m} \mathrm{~s}^{-1}$, long barb represents $5 \mathrm{~m} \mathrm{~s}{ }^{-1}$, pennant represents $25 \mathrm{~m} \mathrm{~s}^{-1}$ ), and absolute vorticity $\left(10^{-5} \mathrm{~s}^{-1}\right.$, shaded). Times shown are (a),(b) 1200 and (c),(d) 1800 UTC 16 Feb 2007.

errors in the low- and midlevel temperature and moisture fields. In the region where the bands developed, forecast near-surface temperatures were generally $1^{\circ}-$ $2^{\circ} \mathrm{C}$ too low, and near-surface dewpoints were $1^{\circ}-5^{\circ} \mathrm{C}$ too low (Fig. 8). Above $500 \mathrm{hPa}$, forecast temperatures were too high, whereas dewpoints were underpredicted to the east of the Continental Divide but overpredicted farther west (Fig. 8). The underprediction of moisture and instability may partially explain why the NAM failed to predict precipitation in eastern Wyoming and Colorado (Fig. 3). A full diagnosis of the reasons for the temperature and moisture errors in the NAM is beyond the scope of this study, but it is possible that the boundary layer parameterization, the land surface model, or both, were responsible for reduced fluxes of heat and moisture in the boundary layer. 

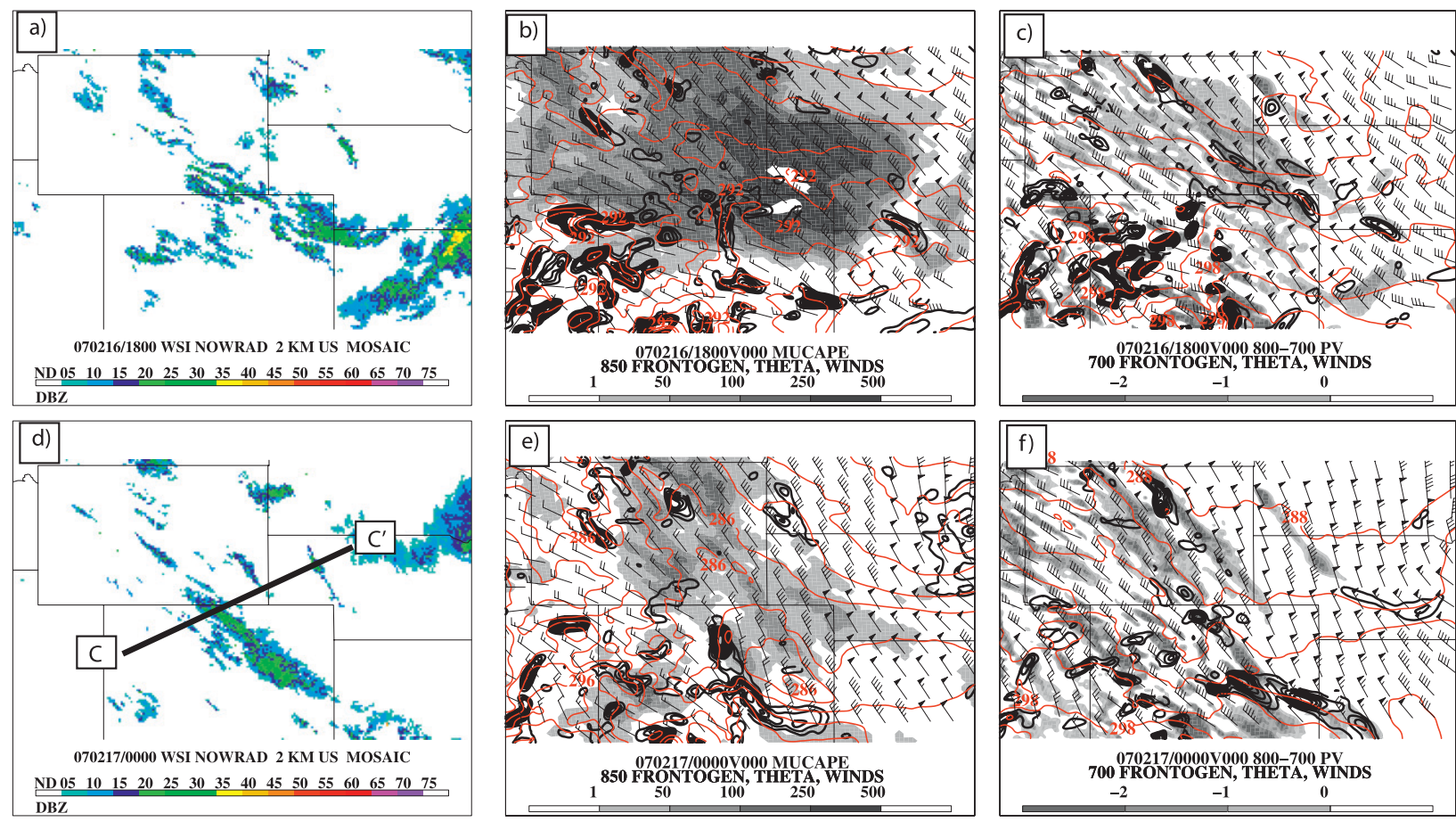

FIG. 7. (a),(d) Observed composite radar reflectivity. (b),(e) NAM analysis of MUCAPE ( $\mathrm{J} \mathrm{kg}^{-1}$, shaded), positive 850-hPa frontogenesis [thick black contours every $1.5 \mathrm{~K}(100 \mathrm{~km})^{-1}(3 \mathrm{~h})^{-1}$ ], potential temperature (red contours every $2 \mathrm{~K}$ ), and winds (short barb represents $2.5 \mathrm{~m} \mathrm{~s}^{-1}$, long barb represents $5 \mathrm{~m} \mathrm{~s}^{-1}$, pennant represents $25 \mathrm{~m} \mathrm{~s}^{-1}$ ). (c),(f) NAM analysis of 800-700-hPa potential vorticity (shaded in PVU, where 1 PVU $\left.=10^{-6} \mathrm{~m}^{2} \mathrm{~s}^{-1} \mathrm{~K} \mathrm{~kg}^{-1}\right), 700-\mathrm{hPa}$ frontogenesis [thick black contours every $1.5 \mathrm{~K}(100 \mathrm{~km})^{-1}(3 \mathrm{~h})^{-1}$ ], potential temperature (red contours every $2 \mathrm{~K}$ ), and winds. The potential temperature and frontogenesis fields have been smoothed with a nine-point smoother for clarity. Times shown are (a)-(c) 1800 UTC 16 Feb and (d)-(f) 0000 UTC 17 Feb 2007. The location of the vertical sections in Fig. 10 is shown by the line $\mathrm{C}^{-\mathrm{C}^{\prime}}$ in (d).

The region of instability and moisture continued to move equatorward during the day. By 0000 UTC, MUCAPE had decreased substantially but was still positive in much of Wyoming and parts of the Colorado and Nebraska (Fig. 7e) as both the major and minor convective bands persisted.

\section{c. Possible physical mechanisms for banded convection}

Two forms of banded convection were observed in this case: the major and minor bands. Given these two types of banding, what physical mechanisms could be responsible for their initiation, organization, and maintenance?

As demonstrated above, the major band was likely initiated by ascent on the warm side of a maximum of frontogenesis in the presence of MUCAPE, indicating sufficient moisture and instability for convection. This band did not follow the movement of the near-surface frontogenesis and MUCAPE maximum equatorward, however. The band instead remained stationary in northern Colorado, where it was more closely aligned with frontogenesis at $700 \mathrm{hPa}$.
The reasons for the development of the minor convective bands, their organization, and their maintenance are not entirely clear. The minor bands developed within weaker frontogenesis and less CAPE than the major band, and they were generally shorter lived than the major band. Two possible explanations for such narrowbanded convection (e.g., Parsons and Hobbs 1983) include gravity waves (e.g., Uccellini and Koch 1987) and horizontal convective rolls (e.g., Weckwerth et al. 1997; Schultz et al. 2004). The lack of regular spacing for the bands and the alignment of the bands parallel to the wind shear and the thermal wind suggest that gravity waves are an unlikely candidate. Similarly, the lack of regular spacing and the depth and intensity of the convection suggest that horizontal convective rolls were not responsible for the banding either.

Idealized numerical modeling studies by Xu (1992) have shown that frontogenesis in the presence of negative moist potential vorticity can produce banded precipitation. Negative moist potential vorticity is an indication of moist symmetric instability when the atmosphere is conditionally and inertially stable [Bennetts and Hoskins 1979; Emanuel 1983a,b; and as reviewed by Schultz and 


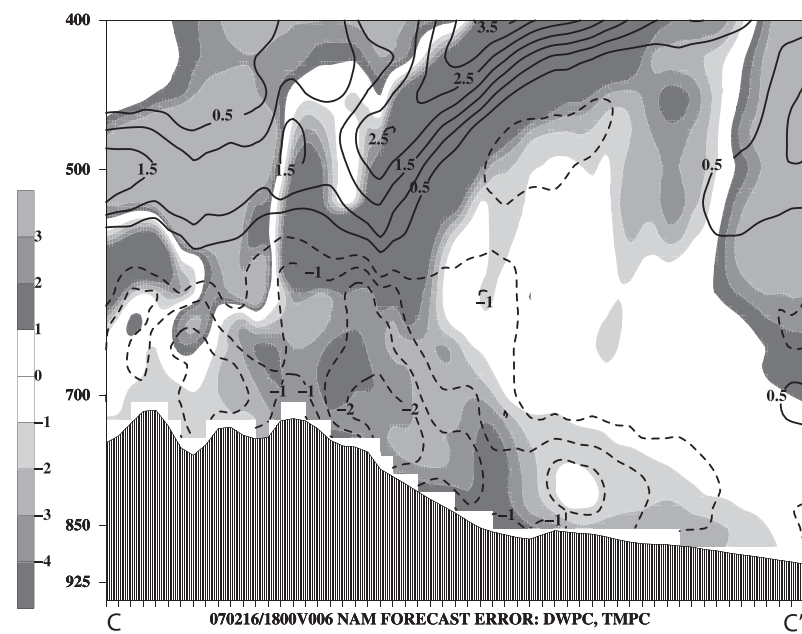

FIG. 8. Vertical cross section showing errors in the 6-h NAM forecast of temperature (contoured every $1 \mathrm{~K}$, with the zero contour omitted and negative contours dashed) and dewpoint (shaded in K), valid at 1800 UTC 16 Feb 2007. The location of the cross section is shown by the line $\mathrm{C}-\mathrm{C}^{\prime}$ in Fig. 7 d. Errors are calculated relative to the 1800 UTC NAM analysis.

Schumacher (1999)]. The bands in this case, however, developed in a generally unsaturated synoptic and mesoscale environment (Fig. 9)-like the banding case discussed by Schultz and Knox (2007) but unlike the banding that occurs in the saturated comma-cloud heads of extratropical cyclones (e.g., Novak et al. 2004, 2006, 2009). Consequently, moist symmetric instability is an unlikely candidate for the bands in this present case.

Several studies have identified banded convection that forms within conditionally unstable upslope flow (e.g., Cosma et al. 2002; Kirshbaum and Durran 2005a,b; Kirshbaum et al. 2007a,b). These studies examined the atmospheric characteristics upstream of topography, and the role of the topography itself, in initiating and organizing these bands. The appearance of the bands in radar imagery in our case is similar to images shown by Kirshbaum and Durran (2005a), but there are two important differences. First, the bands on 16-17 February occurred well downstream of the topography over lower terrain, whereas Cosma et al. (2002) and Kirshbaum and Durran $(2005 a, b)$ examined bands that occurred in primarily upslope flow. Second, the mesoscale environment where the bands formed in this case was generally unsaturated (Fig. 9), whereas the soundings for the upstream environment used by Cosma et al. (2002) and Kirshbaum and Durran (2005a) were nearly saturated at low levels. As a result, it is unclear whether the processes leading to the banding are the same between these cases.

In addition to the presence of conditional instability, the location of this event on the anticyclonic-shear side of an upper-level jet suggests that inertial and dry symmetric

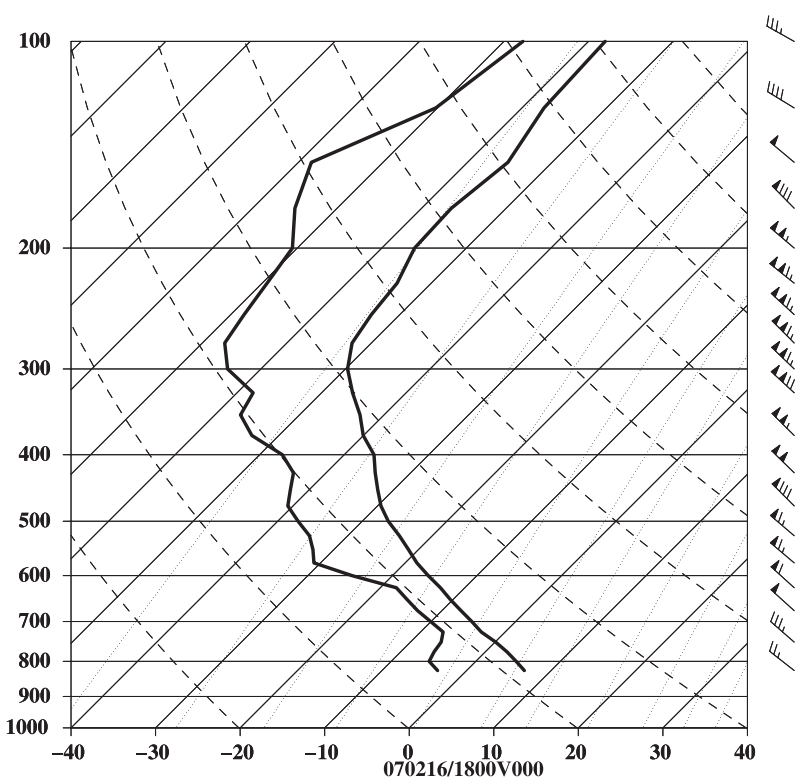

FIG. 9. Skew $T-\log p$ diagram at Fort Collins from the NAM analysis at 1800 UTC.

instabilities may also have been present. Absolute vorticity, when negative, indicates inertial instability, and potential vorticity, when negative and the atmosphere is inertially and gravitationally stable, indicates dry symmetric instability (e.g., Hoskins 1974). In this event, widespread dry symmetric instability at low to midlevels, with smaller areas of inertial instability, were present (Figs. 6b, 6d, 7c, 7f, and 10). Upper-level inertial instability has been argued to increase the intensity of convective systems by enhancing outflow aloft (Blanchard et al. 1998), and Schultz and Knox (2007) have suggested that the release of inertial instability may cause convection to organize into narrow bands.

The presence of these instabilities can be attributed to a midlevel jet streak that moved southeastward throughout the day, and to the nearly well-mixed, baroclinic boundary layer (Fig. 10; e.g., Davis 1997.). Dry symmetric instability was present throughout the regions where bands would develop, whereas inertial instability was limited to smaller areas near the mountains in Colorado (Figs. 6b, 6d, and 10a). The largest magnitudes of negative absolute vorticity appeared to be located near and downstream of the particularly high mountain ranges: the Front Range in Colorado, and the Big Horn and Teton Ranges in northern Wyoming, where the flow appears to have been partially blocked and formed a dipole of vorticity (Fig. 6d; e.g., Rotunno et al. 1999). However, the NAM analyses likely have insufficient resolution to fully resolve these flow features. There also appeared to be larger-scale flow splitting around the Rocky Mountains-with westerly winds throughout Wyoming 


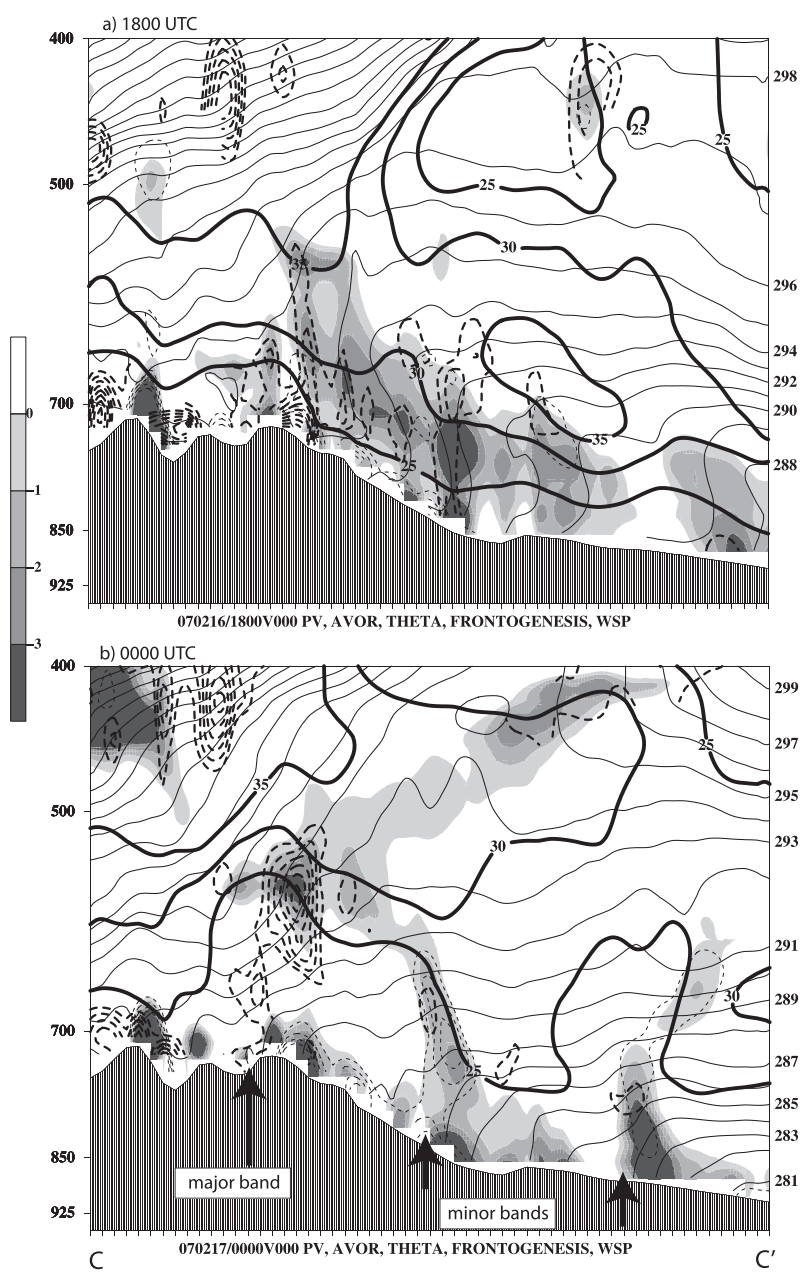

FIG. 10. Cross section through the region where multiple snowbands developed at (a) 1800 UTC 16 Feb and (b) 0000 UTC 17 Feb 2007. Shown are NAM analyses of potential temperature (thin solid contours every $2 \mathrm{~K}$ ), potential vorticity (negative values shaded in PVU), absolute vorticity (negative values contoured in thin dashed lines every $2 \times 10^{-5} \mathrm{~s}^{-1}$ ), positive frontogenesis [thick dashed lines every $\left.1 \mathrm{~K}(100 \mathrm{~km})^{-1}(3 \mathrm{~h})^{-1}\right]$, and wind speed (thick solid contours at 25,30 , and $35 \mathrm{~m} \mathrm{~s}^{-1}$ to emphasize the location of the midlevel jet). The location of the section is shown in Fig. 7d.

turning to a northwesterly direction in western Nebraska and northeastern Colorado-which contributed to the anticyclonic horizontal shear in the regions where the bands developed.

The bands formed in areas where nearly vertical isentropes were intersecting the ground and moving with a component toward higher terrain (Fig. 10). After the major and minor bands formed, some localized regions of reduced wind speed and negative absolute vorticity were analyzed in the NAM up to about $600 \mathrm{hPa}$; the snowbands were located on the anticyclonic-shear side of these inertially unstable regions (Fig. 10). Thus, convection was likely caused by low-level frontogenetical lifting in an environment downstream of mountains that had conditional and dry symmetric instabilities and, in some areas, inertial instability (Figs. 7 and 10).

The presence of these instabilities does not necessarily imply that they were released during this event, or that they were important to the organization and maintenance of the banded convection. The specific effects of the terrain are also unclear. Furthermore, the small scale on which the bands occurred, and the inability of the operational NAM forecast to predict them, raises the question of whether a model with higher resolution that explicitly predicts convection may provide a better forecast of these bands. With these issues in mind, we use high-resolution numerical simulations to explore in more depth the processes that led to the development and maintenance of the observed banded snowfall.

\section{Simulations}

To address the formation mechanisms in more detail, convection-permitting simulations of this case were performed. Section 3a describes the configuration of the model and the details of the numerical experiments, section $3 b$ describes the results of the simulations, and section $3 c$ discusses the processes that may have been involved in the formation, organization, and persistence of the simulated bands.

\section{a. Model configuration}

Version 2.2 of the Advanced Research version of the WRF model (WRF-ARW; Skamarock et al. 2008) was run at convection-permitting resolutions to simulate the 16-17 February 2007 event. In the set of simulations presented herein, the model was initialized at 1200 UTC 16 February 2007 and integrated for $12 \mathrm{~h}$. NAM model analyses with $40-\mathrm{km}$ horizontal grid spacing were used to initialize the model and for lateral boundary conditions at $12-\mathrm{h}$ intervals. The vertical grid consisted of 48 levels and was stretched such that its finest grid spacing (about $100 \mathrm{~m}$ ) was in the boundary layer and gradually became coarser with height to a maximum grid spacing of about $1.5 \mathrm{~km}$ near the model top at about $20 \mathrm{~km}$. The simulations presented herein take advantage of a two-way nested-grid configuration and included simulations with two, three, and four domains (Fig. 11). The innermost domain had a horizontal grid spacing of $1 \mathrm{~km}$. The parameterization schemes used and other details of the model configuration are shown in Table 1, as are the parameterization schemes that were used in the operational NAM forecast discussed previously. 


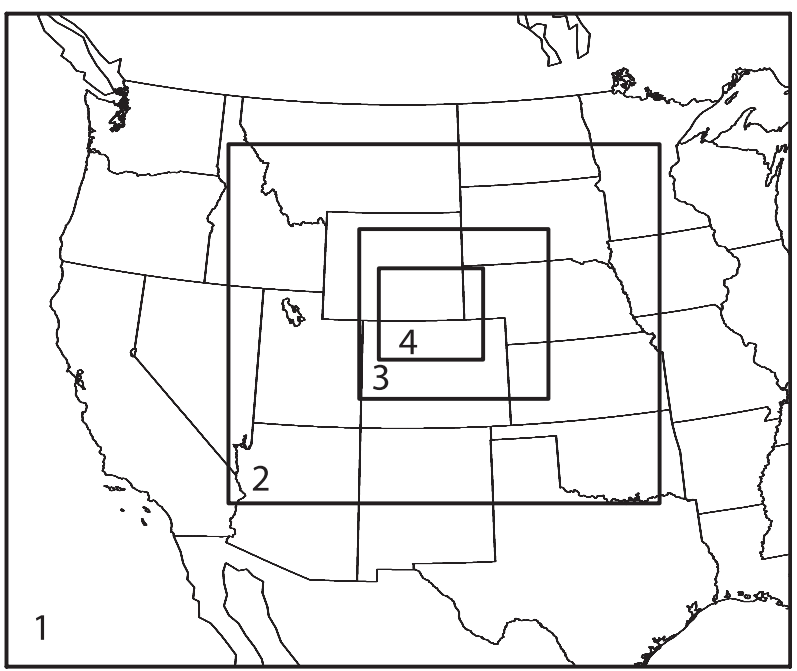

FIG. 11. Locations of model domains. The horizontal grid spacing is $27 \mathrm{~km}$ on domain $1,9 \mathrm{~km}$ on domain 2, $3 \mathrm{~km}$ on domain 3 , and $1 \mathrm{~km}$ on domain 4 .

\section{b. Simulated environmental conditions and band development}

The first simulation that was performed used the two largest of the four domains in Fig. 11 and Table 1. This simulation is referred to as $9 \mathrm{KM}$ because the grid with the finest resolution in this run had a horizontal grid spacing of $9 \mathrm{~km}$. The $9 \mathrm{KM}$ simulation produced precipitation in eastern Wyoming, western Nebraska, and northeastern Colorado that had both a cellular and banded appearance (Fig. 12a). This run improved on the operational NAM forecast by predicting precipitation in the general area where it was observed (whereas the NAM forecast had none; Fig. 3b). Thus, it appears that the NAM's inability to predict precipitation was not solely related to resolution, as the NAM and the $9 \mathrm{KM}$ simulation had similar grid spacing ( 9 versus $12 \mathrm{~km}$ ). The $9 \mathrm{KM}$ run, which included both parameterized and explicitly predicted precipitation, had some suggestion of precipitation bands but did not have the distinct banded structures that were observed.

The next simulation added a third domain, with horizontal grid spacing of $3 \mathrm{~km}$. Hereinafter, this simulation will be referred to as $3 \mathrm{KM}$. The $3 \mathrm{KM}$ simulation, with only explicit convection, succeeded in producing precipitation bands similar in appearance to the observed bands; however, the location and timing were incorrect (Figs. 13a, 13d, and 13g), similar to what has been found in other convection-permitting simulations (e.g., Roebber et al. 2004; Kain et al. 2008; Weisman et al. 2008; Lean et al. 2008; Schwartz et al. 2009).

At 1800 UTC, the simulated precipitation field was generally similar to that in the observations, with the
TABLE 1. Design of the WRF-ARW version 2.2 numerical model experiments, compared to the configuration of the operational NAM. Multiple entries indicate different configurations for domains 1-4. See Fig. 11 for domain locations. Technical descriptions of the parameterizations are available online in Skamarock et al. (2008).

\begin{tabular}{|c|c|c|}
\hline Setting & WRF-ARW & $\begin{array}{c}\text { Operational } \\
\text { NAM }\end{array}$ \\
\hline $\begin{array}{l}\text { Horizontal grid } \\
\text { spacing }(\mathrm{km})\end{array}$ & $27.0,9.0,3.0,1.0$ & 12 \\
\hline Vertical levels & $48,48,48,48$ & 60 \\
\hline Time step (s) & $162,54,18,6$ & 27 \\
\hline $\begin{array}{l}\text { Initial and } \\
\text { boundary } \\
\text { conditions }\end{array}$ & 40-km NAM & NAM \\
\hline $\begin{array}{l}\text { Cumulus } \\
\text { convection }\end{array}$ & $\begin{array}{l}\text { Kain (2004), Kain } \\
\text { (2004), explicit, } \\
\text { explicit }\end{array}$ & Janjić (1994) \\
\hline Boundary layer & Yonsei University & $\begin{array}{l}\text { Mellor-Yamada- } \\
\text { Janjić }\end{array}$ \\
\hline Surface layer & Monin-Obukhov & Janjić Eta Model \\
\hline Microphysics & $\begin{array}{l}\text { Thompson et al. } \\
\text { (2008) }\end{array}$ & Ferrier \\
\hline Land surface & Noah & Noah \\
\hline Shortwave radiation & Dudhia (1989) & GFDL \\
\hline Longwave radiation & Rapid radiative transfer & GFDL \\
\hline Diffusion & $\begin{array}{l}\text { Sixth-order monotonic } \\
\text { (Knievel et al. 2007) }\end{array}$ & N/A \\
\hline Scalar advection & Positive definite & Positive definite \\
\hline
\end{tabular}

loosely organized precipitation that would become part of the major band along the Colorado-Nebraska border (Fig. 13a). The simulated precipitation and the low-level frontogenesis maximum were located slightly north of the corresponding features in the observations (cf. Figs. $13 \mathrm{a}-\mathrm{c}$ and $7 \mathrm{a}-\mathrm{c}$ ). Between 1800 and 2100 UTC, several narrow bands also developed in southern Wyomingnorthern Colorado and in Nebraska, similar to the observed minor bands (Fig. 7d). The minor bands in the model were too slow to develop; whereas the bands had formed by 1715 UTC in the observations, they did not develop until between 1900 and 2000 UTC in the model. The major band was also not as intense or as long lived in the simulation as it was in the observations. Three hours later at 0000 UTC, the modeled major band had moved equatorward and westward, and a series of bands of different widths and lengths remained over Wyoming and Colorado (Fig. 13g). As in the observations and the NAM analysis, the primary near-surface frontogenesis maximum moved equatorward through the day and was located south of the banded convection by 0000 UTC (Figs. 13e and 13h). A northwest-southeast-oriented region of 850-hPa frontogenesis did remain in southeastern Wyoming and northern Colorado, however (Fig. 13h). Some narrow regions of frontogenesis, especially at the 700-hPa level (Figs. 13c, 13f, and 13i), were also present. 
a) 9KM WRF Simulated 6-hr Precipitation (mm)

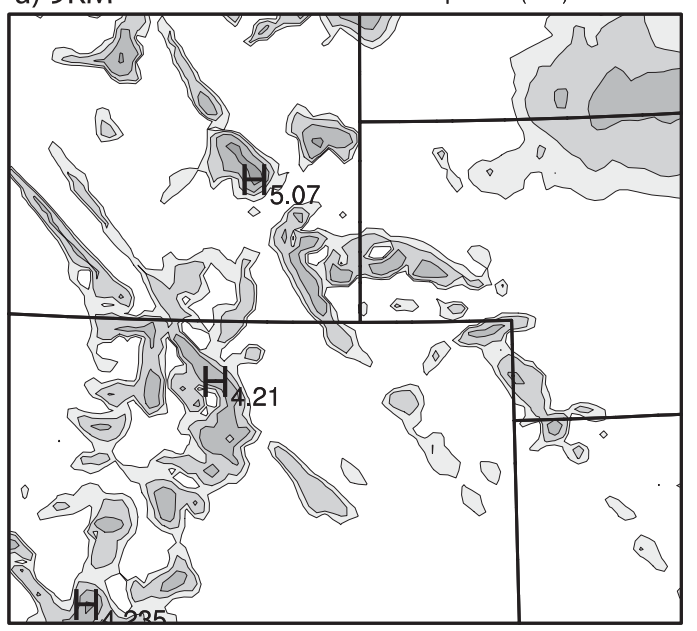

b) $3 K M \quad$ WRF Simulated 6-hr Precipitation (mm)

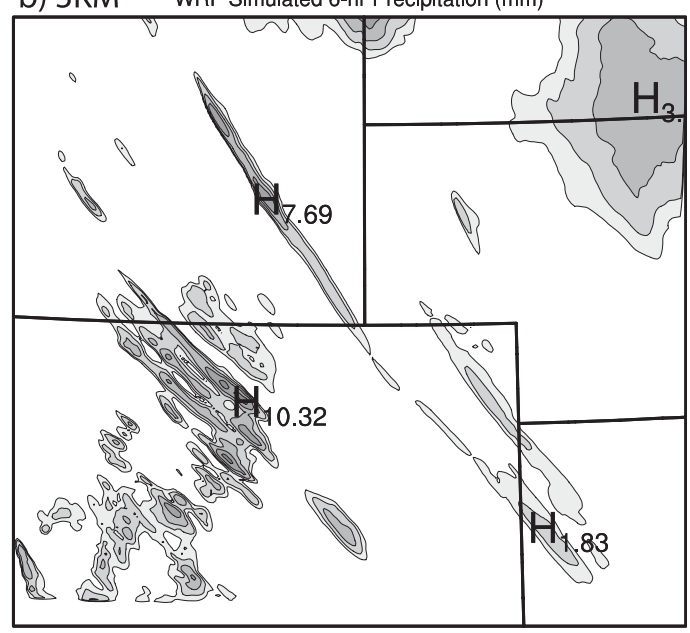

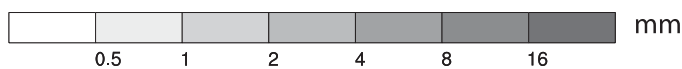

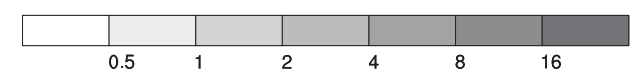

FIG. 12. As in Fig. 3, but for the simulated precipitation from model runs (a) 9 KM and (b) 3 KM.

These may have been partly caused by flow around topography and by the convective bands themselves, hypotheses that will be analyzed further in the next subsection.

Overall, the simulated precipitation in this run improved greatly on the NAM forecast by indicating the potential for banded convective precipitation on the plains (cf. Figs. $12 \mathrm{~b}$ and $3 \mathrm{~b}$ ). The results of this simulation, despite its errors in the timing and placement of the bands, demonstrate that a numerical model was able to provide a reasonable representation of both types of banded convection (major and minor bands) and was able to improve upon the operational forecast without requiring assimilation of mesoscale data. Thus, given the formation of both the major band and the minor bands, our simulation can be employed to explore the physical processes in this event, with a larger aim of understanding how such bands develop in nature.

\section{c. Ingredients for simulated snowbands}

In this section, we diagnose the ingredients for banded convection in the 16-17 February 2007 event from the $3 \mathrm{KM}$ model simulation and compare our results to the NAM-analyzed environmental conditions in sections $2 b$ and $2 \mathrm{c}$. The simulation provided a realistic representation of the cold front and associated frontogenesis (cf. Figs. 7 and 13). Similar to what was shown in the NAM, there was positive MUCAPE in most of the region where the simulated bands formed, with values over $200 \mathrm{~J} \mathrm{~kg}^{-1}$ in some areas (Figs. 13b, 13e, and 13h). However, the values of MUCAPE were somewhat smaller than in the NAM analysis, which may explain the slightly delayed onset of convection in our simulation compared with the observations. There was relatively dry air at all levels, with steep lapse rates below about $625 \mathrm{hPa}$ (cf. Figs. 9 and 14).

Because of the higher temporal and spatial resolutions of this simulation in comparison with the NAM, the detailed structure of the flow near the mountains can be examined to determine how it may have affected the development and organization of the snowbands. At 1800 UTC, the midlevel jet was moving southeastward to the east of the high terrain, and a widespread region of negative potential vorticity was present on its anticyclonic-shear flank (Figs. 15a and 15b). The regions of negative absolute vorticity were slightly narrower in the simulation in comparison to the analysis, but they appeared in similar locations (cf. Figs. 15b and 6d). These elongated inertially unstable regions, in some cases with absolute vorticity maxima alongside them, were located directly downstream of mountain ranges (Fig. 15b) where the wind speed was reduced (Fig. 15a). The decrease in wind speed in the wake of an obstacle creates strong horizontal shear and a corresponding couplet of vorticity and potential vorticity (Rotunno et al. 1999). These features are often referred to as PV banners, and they have been detected downstream of the Alps (e.g., Schär et al. 2003; Jiang et al. 2003; Grubišić 2004; Flamant et al. 2004). In run 3 KM, they were most prominent downstream of the Big Horn Mountains in Wyoming and the Black Hills (Figs. 15c and $15 \mathrm{~d}$ ), but they also occurred downstream of other areas of elevated terrain. The shearing deformation associated with these banners may have also led to some of 

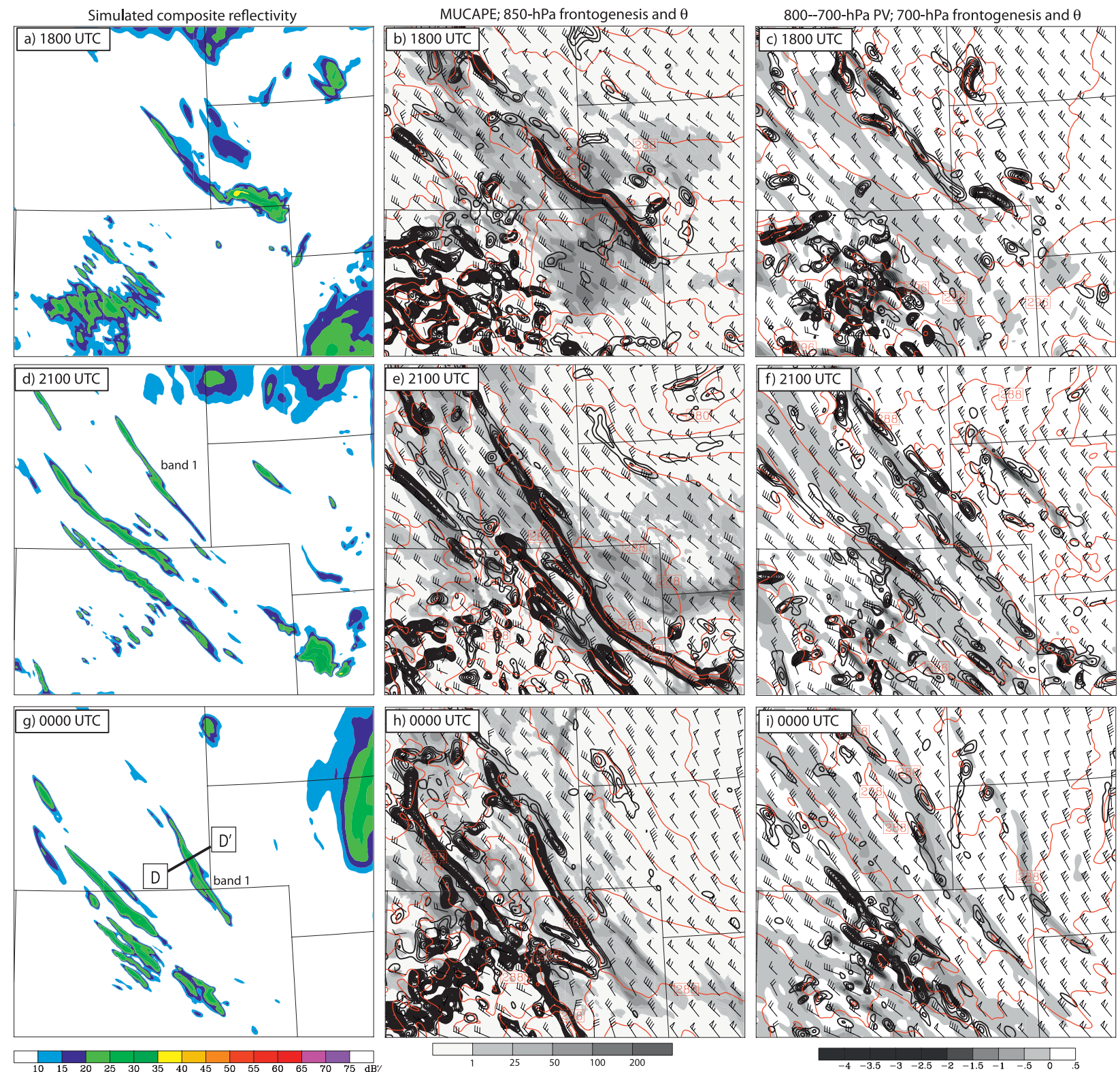

FIG. 13. As in Fig. 7, but for model-simulated fields from run 3 KM. The times shown are (a)-(c) 1800 UTC 16 Feb, (d)-(f) 2100 UTC 16 Feb, and (g)-(i) 0000 UTC 17 Feb 2007. The locations of the cross sections in Figs. 16-17 are shown in (g), and band 1 is discussed in the text.

the narrow regions of elevated frontogenesis that are apparent in eastern Wyoming, eastern Colorado, and western Nebraska in Figs. 13c, 13f, and 13i.

Additional regions of inertial instability also developed in association with both frontal lifting and with the convection itself. One particular such region can be seen in western Nebraska at 2100 UTC (Figs. 13d-f and $15 \mathrm{c}, \mathrm{d})$. This formation of inertial instability results from the lifting of low-momentum air near the surface to a level where winds are stronger, creating a deficit of momentum and strong horizontal gradients in the wind speed (e.g., Holt and Thorpe 1991; Blanchard et al. 1998; Novak et al. 2008). Inertial instability develops on the anticyclonic-shear edge of this wind speed gradient (Fig. 15c and 15d). This process is also similar to the development of storm-scale PV dipoles on the edges of convective updrafts that has been discussed by Chagnon and Gray (2009). The creation of this horizontal wind speed gradient and corresponding inertial instability was also present on a slightly larger spatial scale in the NAM analysis (Fig. 10b) and will be shown in the model output in more detail in the next subsection. 


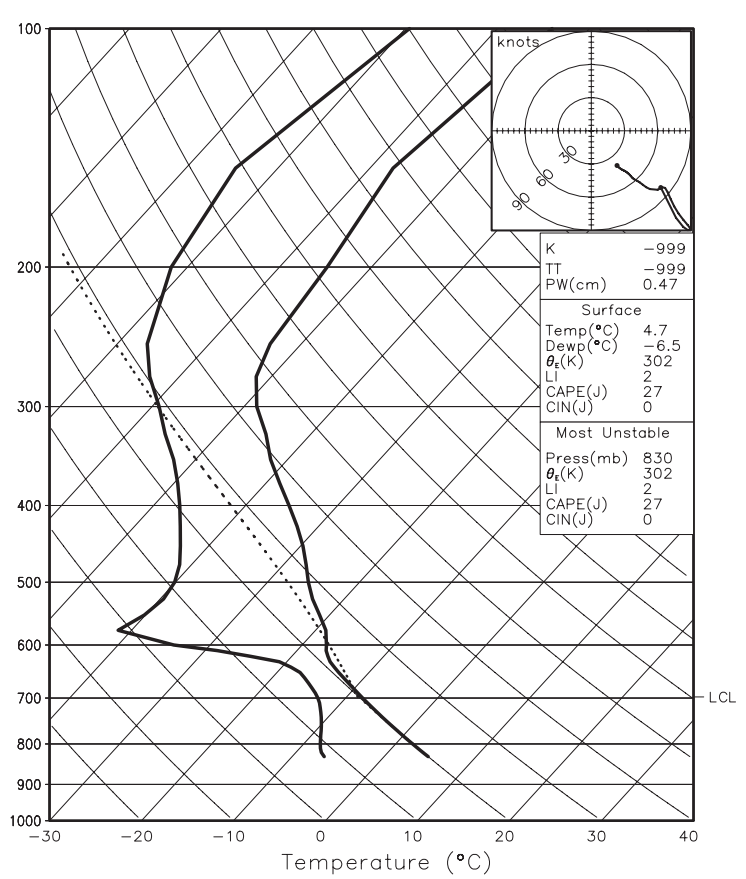

FIG. 14. As in Fig. 9, but for simulation 3 KM at 1800 UTC.

The vertical structure of the atmosphere in the region where the bands developed was also similar to that in the analysis (not shown). Both the major and minor convective bands developed within the baroclinic, nearly well-mixed boundary layer where widespread dry symmetric instability was present and smaller areas of inertial instability existed. Positive CAPE, which was maximized at the surface, was also present across the areas where the bands formed (Figs. 13b, 13e, and 13h).

\section{d. Detailed analysis of the development and evolution of the simulated bands}

In this section, we examine the development and evolution of one of the convective bands in simulation $3 \mathrm{KM}$ in more detail: the long-lived band in southeast Wyoming and northern Colorado marked as band 1 in Fig. 13d. Although not shown explicitly in Fig. 13, the band that was located in southeastern Wyoming at 1800 UTC (Fig. 13a) moved southeastward out of that area between 1800 and 2100 UTC, and band 1 was a new band that developed after 2000 UTC.

Band 1 was initiated within a region of positive CAPE that was generally maximized at the surface, although elevated CAPE (i.e., CAPE for parcels originating above the boundary layer) was also present (Fig. 16). The air was dry near the surface (e.g., Fig. 14), but there was a near-saturated layer at approximately $700 \mathrm{hPa}$ (Fig. 16) where precursor clouds developed (not shown). These clouds, and the banded convection, formed within areas of frontogenetical lifting along steeply sloped isentropes (Figs. 17a and 17b). Prior to the initiation of band 1 at 2000 UTC, there was widespread dry symmetric instability at low levels on the western flank of the midlevel jet (Fig. 17a), with a region of negative absolute vorticity extending up to nearly $500 \mathrm{hPa}$ (at $x=35$ $45 \mathrm{~km}$ in Fig. 17a). This deep region of inertial instability was associated with a vorticity banner that extended downstream from the Big Horn Mountains in Wyoming (Fig. 15). There were two maxima in frontogenesis: one at the surface (at $x=25-35 \mathrm{~km}$ in Fig. 17a) and one above the surface to the northeast of the surface maximum (at $x=35-45 \mathrm{~km}$ ). The surface frontogenesis had corresponding ascent (at $x=25-30 \mathrm{~km}$ in Fig. 16a), but there was no precipitation associated with this ascent. Between 2000 and 2100 UTC, the surface-based frontogenesis moved westward along the surface baroclinic zone, whereas the elevated frontogenesis maximum grew and strengthened slightly (Fig. 17b). Between 2100 and 2200 UTC, convection was initiated above the elevated frontogenesis and along the low-momentum edge of the vorticity banner (Figs. 16c and 17c). Snow began to reach the ground at this time, and the convective band intensified further between 2200 and 2300 UTC (Figs. 16d and $17 d)$.

To determine the properties of the air that rose in the convective band, backward parcel trajectories were calculated. Eleven parcels that were located within band 1 at 2300 UTC at $550 \mathrm{hPa}$ (the level where the updraft was maximized; Fig. 16d) were selected, and trajectories were calculated back $3 \mathrm{~h}$ to 2000 UTC. These parcels all approached from the northwest, within the strong northwesterly flow (Fig. 18). The parcels all originated below $600 \mathrm{hPa}$, with most originating between 800 and $650 \mathrm{hPa}$ (Fig. 19a). Along the parcels' paths, there was both surface-based CAPE and an elevated maximum of CAPE for parcels between 700 and $600 \mathrm{hPa}$ (Fig. 19a). As the parcels progressed toward the southeast, they entered a region of elevated frontogenesis (Figs. 19a and $19 \mathrm{~b}$ ), which is the same region of frontogenesis that was apparent in the across-band plane in Fig. 17. With both CAPE and lift present in this location, the parcels rose and released the instability (Fig. 19b). These trajectories also suggest that even though surface-based CAPE was present, it was in fact elevated air that rose in the banded convection. This is consistent with the results discussed in the previous paragraph and shown in Fig. 16, that convection did not develop in association with the surface-based frontogenesis and CAPE, but did with the elevated frontogenesis and CAPE. It is possible that this was a result of the low relative humidity near the surface, such that the surface-maximized frontogenesis was unable to lift parcels to saturation, but elevated parcels 

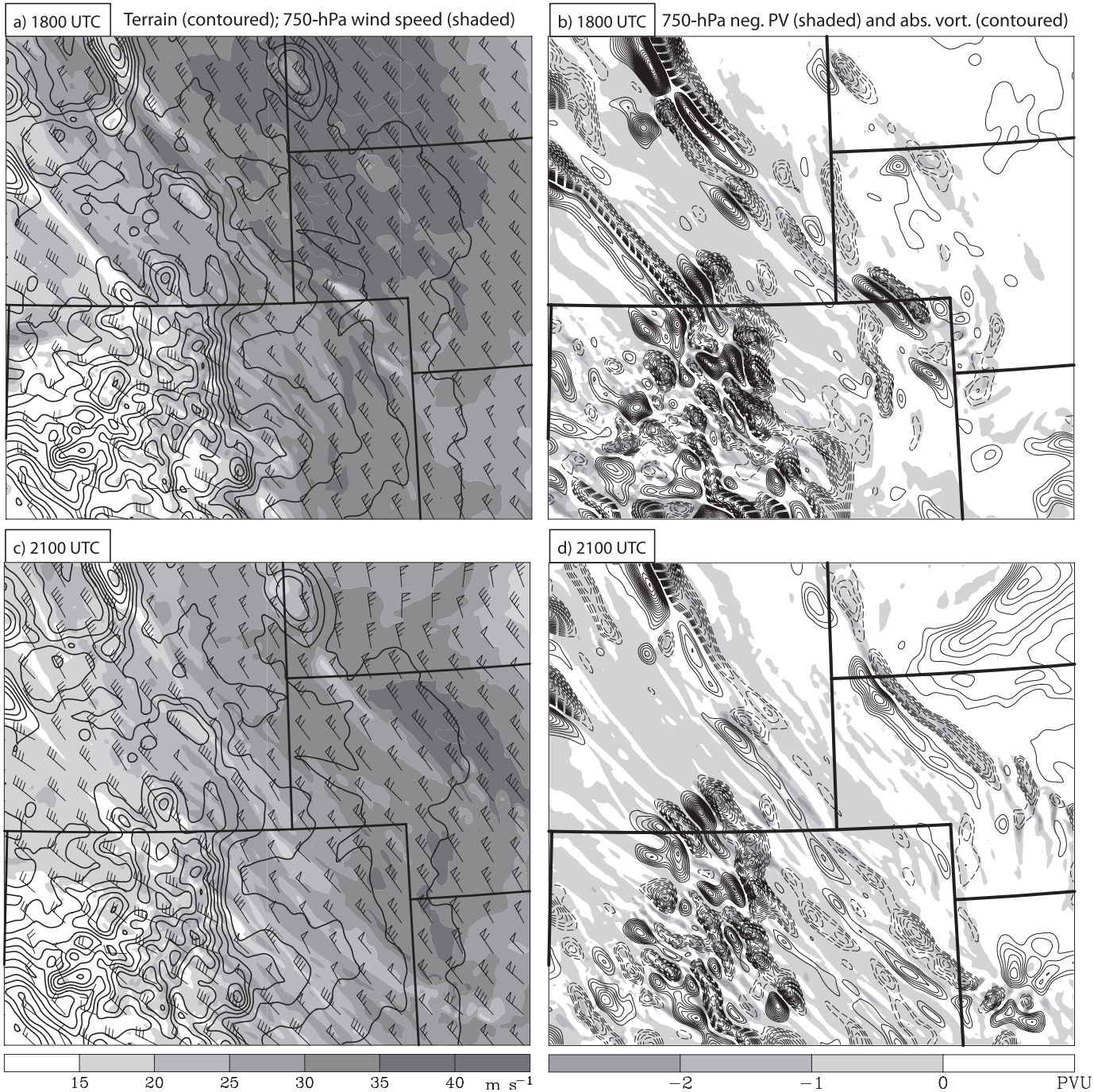

FIG. 15. (a),(c) The 750-hPa wind speed ( $\mathrm{m} \mathrm{s}^{-1}$, shaded), winds (short barb represents $2.5 \mathrm{~m} \mathrm{~s}^{-1}$, long barb represents $5 \mathrm{~m} \mathrm{~s}^{-1}$, pennant represents $25 \mathrm{~m} \mathrm{~s}^{-1}$ ), and terrain height (contoured every $500 \mathrm{~m}$ above $1000 \mathrm{~m}$; field has been smoothed for clarity) from run 3 KM. (b),(d) The 750-hPa potential vorticity (PVU, negative values shaded) and absolute vorticity (negative values in dashed contours every $5 \times 10^{-5} \mathrm{~s}^{-1}$ starting at zero; positive values in solid contours starting at 20) from run 3 KM. Times shown are (a),(b) 1800 UTC 16 Feb and (c),(d) 2100 UTC 16 Feb 2007.

(which had higher relative humidity) were able to attain saturation.

As the bands and their associated latent heat release intensified, frontogenesis increased further because of increased lower-tropospheric convergence into the band (Figs. 17c and 17d), a result consistent with the idealized numerical simulations of Thorpe and Emanuel (1985) and the case study simulations of Novak et al. (2009). Also, the convection altered the absolute vorticity and the potential vorticity (e.g., Raymond and Jiang 1990; Chagnon and Gray 2009). Within the convective circulations, the negative absolute vorticity (inertial instability) was neutralized, suggesting that the release of this instability may have played a role in the organization of the convection into bands. On the edges of the bands, however, new regions of strongly negative potential vorticity and absolute vorticity were formed and extended above $450 \mathrm{hPa}$ as low-momentum air was transported upward (Fig. 17d), similar to the processes discussed by Holt and Thorpe (1991), Blanchard et al. (1998), Novak et al. (2008), and Chagnon and Gray (2009).

In summary, the detailed picture painted by the results in this section, along with the larger-scale view presented previously using both the NAM analyses and 
a) 2000 UTC

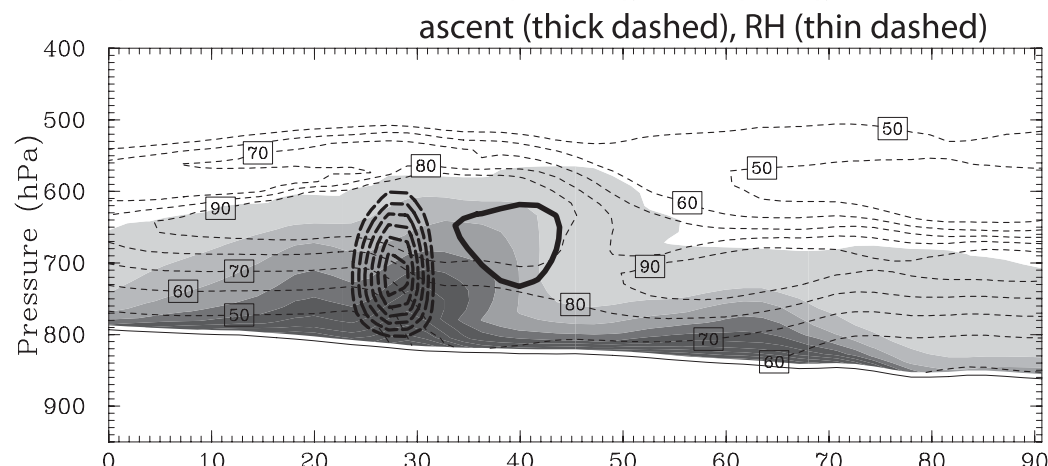

b) 2100 UTC
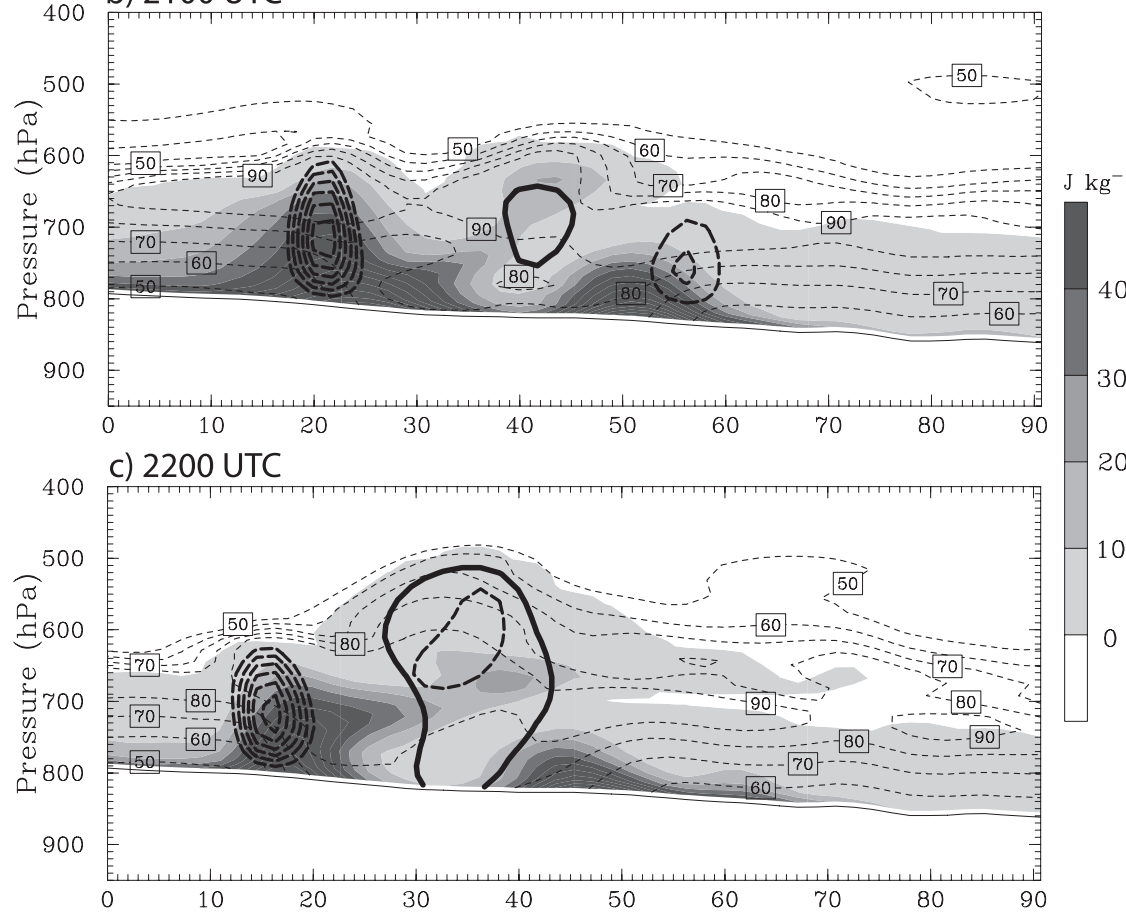

d) 2300 UTC

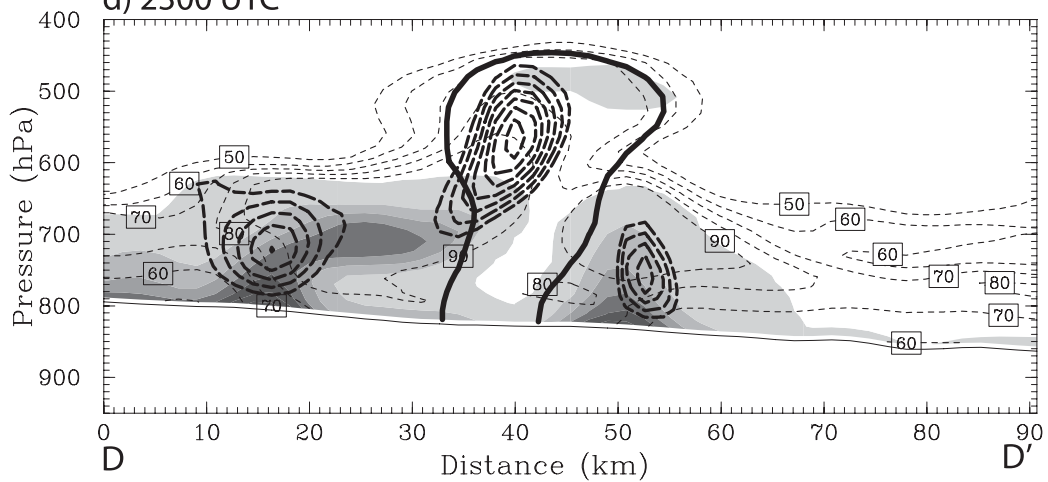

FIG. 16. Vertical cross sections across band 1 in southeastern WY along line D-D' shown in Fig. 13g from simulation $3 \mathrm{KM}$. Fields shown are CAPE of a parcel lifted from each level $\left(\mathrm{J} \mathrm{kg}^{-1}\right.$, shaded), relative humidity with respect to water (thin dashed contours every $10 \%$ above $50 \%$ ), snow mixing ratio (the $0.1 \mathrm{~g} \mathrm{~kg}^{-1}$ contour is shown in thick solid), and pressure vertical velocity $\left(\mathrm{dPa} \mathrm{s}{ }^{-1}\right.$, thick dashed contours with negative values contoured every $10 \mathrm{dPa} \mathrm{s}^{-1}$ starting at $-10 \mathrm{dPa} \mathrm{s}^{-1}$ ). Times shown are (a) 2000, (b) 2100, (c) 2200, and (d) 2300 UTC 16 Feb 2007. Values have been averaged across 10 grid points $(30 \mathrm{~km})$ on either side of the line shown in Fig. 13g. 
a) 2000 UTC PV (shaded), $\theta$ (thin), wind speed (thick),

frontogenesis (thick dashed), neg. abs. vort. (thin dashed)
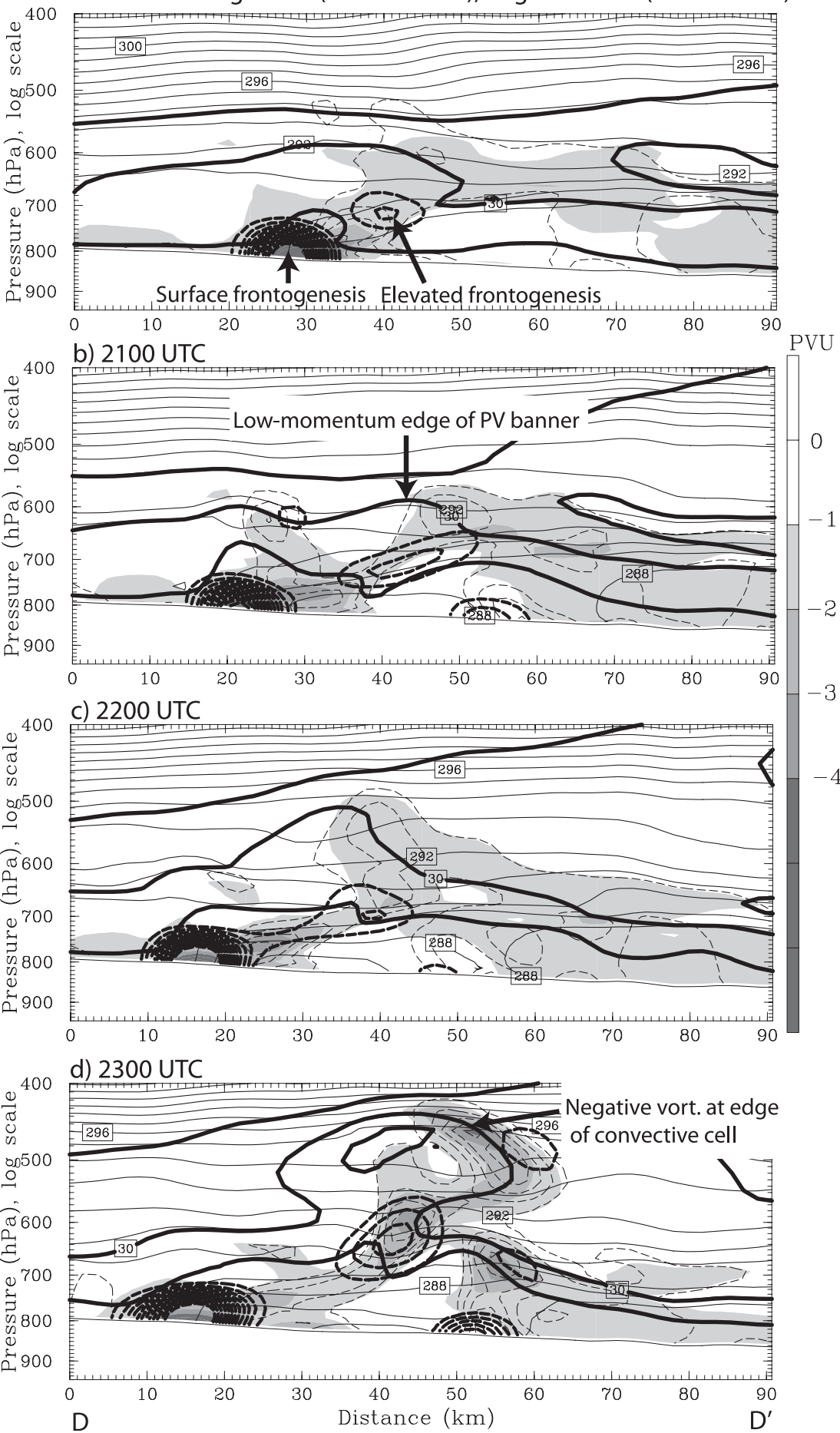

FIG. 17. Vertical cross sections across band 1 in southeastern WY along line D-D' shown in Fig. $13 \mathrm{~g}$ from simulation $3 \mathrm{KM}$. Fields contoured are potential temperature (thin solid contours every $2 \mathrm{~K}$ ), potential vorticity (negative values shaded in PVU), absolute vorticity (negative values contoured in thin dashed lines every $2.5 \times 10^{-4} \mathrm{~s}^{-1}$ ), frontogenesis [thick dashed lines every $5 \mathrm{~K}(100 \mathrm{~km})^{-1} \mathrm{~h}^{-1}$ above 5], and wind speed (thick solid contours at 25, 30 , and $35 \mathrm{~m} \mathrm{~s}^{-1}$ to emphasize the location of the midlevel jet). Times shown are (a) 2000, (b) 2100, (c) 2200, and (d) 2300 UTC 16 Feb 2007. Values have been averaged across 10 grid points $(30 \mathrm{~km})$ on either side of the line shown in Fig. 13g. 


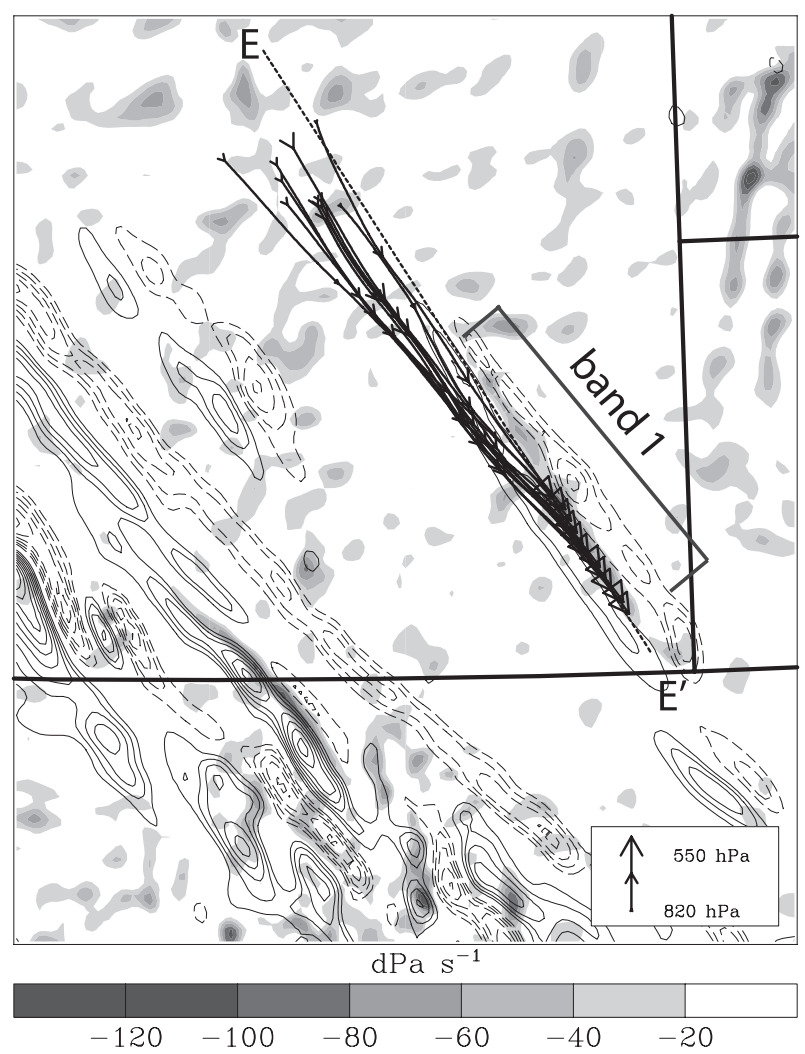

FIG. 18. Vertical velocity (negative values shaded in $\mathrm{dPa} \mathrm{s}^{-1}$ ) and absolute vorticity (negative values in dashed contours every $15 \times$ $10^{-5} \mathrm{~s}^{-1}$ starting at zero; positive values in solid contours starting at 30) from simulation $3 \mathrm{KM}$ at $550 \mathrm{hPa}$ at $2300 \mathrm{UTC} 16 \mathrm{Feb} 2007$. Also shown are the locations of backward parcel trajectories, from 2000 to $2300 \mathrm{UTC}$, for parcels that rose in band 1 to $550 \mathrm{hPa}$ (solid lines with arrows). Larger arrowheads represent lower pressure, according to the legend in the lower right. The dashed line shows the locations of the vertical cross sections in Fig. 19.

the numerical simulation, suggest that the convective bands in this case

- occur in the presence of conditional instability (i.e., CAPE);

- occur in the presence of dry symmetric instability or inertial instability;

- occur along strong low-level gradients of density (i.e., potential temperature), terrain, or both;

- occur on the anticyclonic-shear edge of an inertially or symmetrically unstable region, which in some cases is a vorticity banner downstream of high terrain; and

- generate additional inertial, symmetric instability, or both.

\section{e. Sensitivity to horizontal grid spacing}

Given the relatively small horizontal scale of the banded convection, an additional nested grid with $1-\mathrm{km}$ horizontal grid spacing was added (domain 4 in Fig. 11), which will be termed run $1 \mathrm{KM}$. More detail in the structure of the bands was present in run $1 \mathrm{KM}$ than in $3 \mathrm{KM}$, and there were differences in the locations of some of the bands, but the essential features of the minor bands were captured (cf. Figs. 20a,b and 13d,g). At 2100 UTC, the bands in $1 \mathrm{KM}$ appeared similar to those in the coarser-resolution runs (cf. Figs. 20a and 13d), but by $0000 \mathrm{UTC}$ the most prominent snowband in $1 \mathrm{KM}$ was located somewhat west of that in $3 \mathrm{KM}$ (cf. Figs. 20b and 13g). There was also more cellular structure to the convection over the mountains in $1 \mathrm{KM}$, as well as the appearance of some even narrower bands than were present in $3 \mathrm{KM}$. This result represents a slight improvement in the position of the simulated band in relation to the observations, although the essential aspects of the two simulations are similar. These findings of only moderate improvement of simulations at increasing resolution in going from 3-4-km grid spacing to $1-2-\mathrm{km}$ grid spacing are similar to other studies that have examined the effects of model resolution on convection (e.g., Bryan et al. 2003; Kain et al. 2008; Schwartz et al. 2009).

\section{Discussion}

In section 4a, we compare the 16-17 February 2007 event to other similar events in the western United States and in the previous literature, indicating a common synoptic pattern for such banded convective snowbands along the Front Range of the Rocky Mountains. These results motivate a comparison to previously developed conceptual models that is presented in section $4 \mathrm{~b}$, specifically to banding in northeast U.S. cyclones and orographic precipitation bands. Section $4 c$ compares our findings to past research on vorticity banners, and section $4 \mathrm{~d}$ discusses challenges associated with numerically predicting convective snowbands.

\section{a. Comparison to other cases of banded convection}

After we began studying this event, we began to see other wintertime banded convective events in the western United States that were similar to this case. In particular, two additional cases also occurred on the anticyclonicshear side of a midlevel jet streak that had a combination of both a wide band and narrow convective bands. The first case occurred on 30 November-1 December 2008 in a similar location to the 16 February 2007 event, when two separate periods of multiply banded convection developed: one in eastern Colorado on 30 November (Figs. 21a-c) and one in southern Wyoming, western Nebraska, and eastern Colorado on 1 December (Figs. 21d-f). The second case took place in southern Montana on 12 January 2009 (Figs. 21g-i). The synoptic-scale conditions for both of these cases were similar to the 


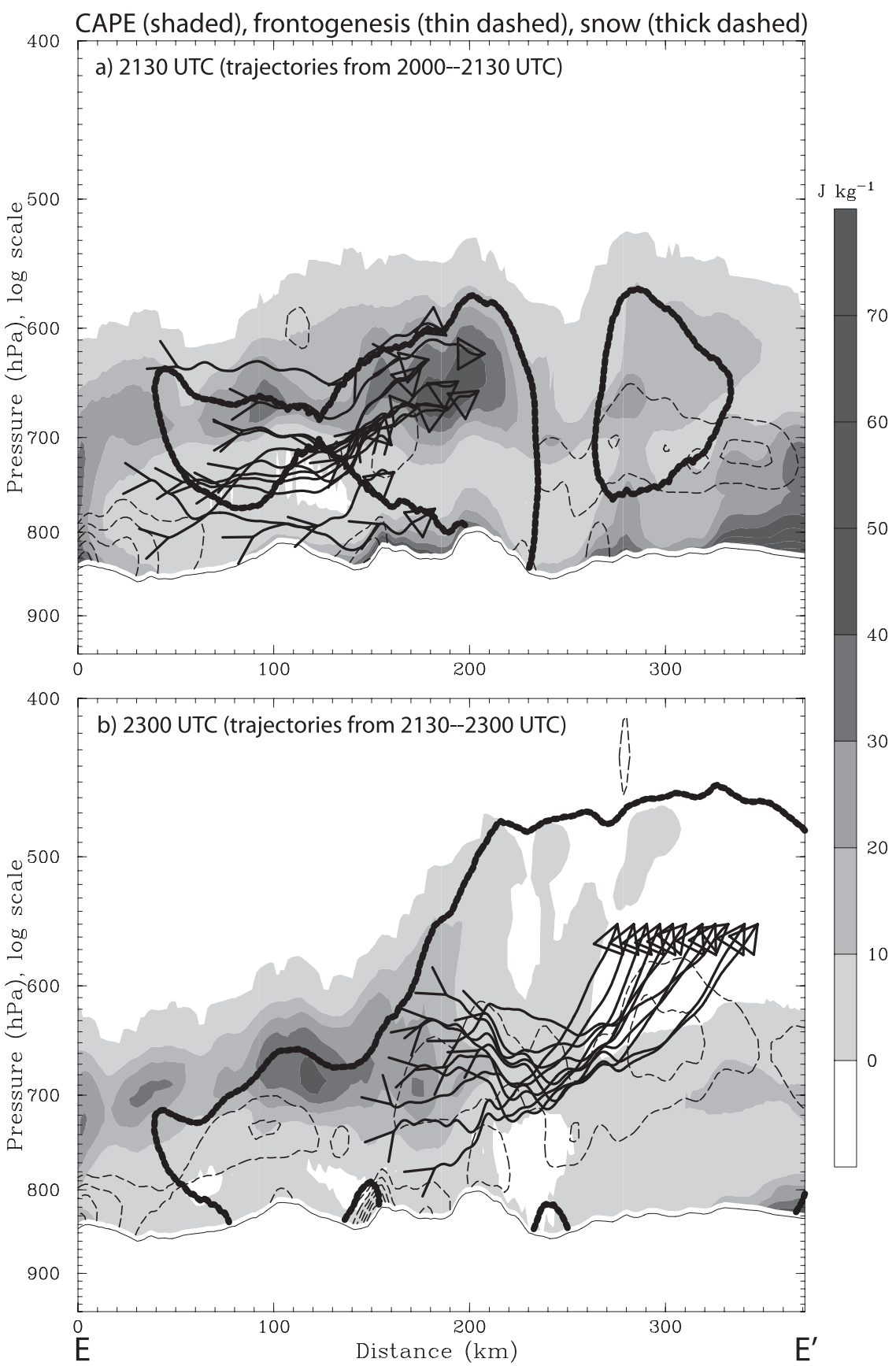

FIG. 19. Vertical cross sections along band 1 in southeastern WY, along line E-E' shown in Fig. 18 from simulation $3 \mathrm{KM}$. Fields shown are the CAPE of a parcel lifted from each level $\left(\mathrm{J} \mathrm{kg}^{-1}\right.$, shaded), frontogenesis [thin dashed lines every $5 \mathrm{~K}(100 \mathrm{~km})^{-1} \mathrm{~h}^{-1}$ above 5], and snow mixing ratio (the $0.1 \mathrm{~g} \mathrm{~kg}^{-1}$ contour is shown in thick dashed). Also shown are the vertical representations of the backward parcel trajectories shown in Fig. 18. (a) The contoured fields at 2130 UTC, with the parcel paths from 2000 to 2130 UTC, and (b) the fields at 2300 UTC with the parcel paths from 2130 to 2300 UTC. Open arrowheads represent the starting points of the trajectories; closed triangles represent the ending points. Values have been averaged across two grid points $(6 \mathrm{~km})$ on either side of the line shown in Fig. 18. 

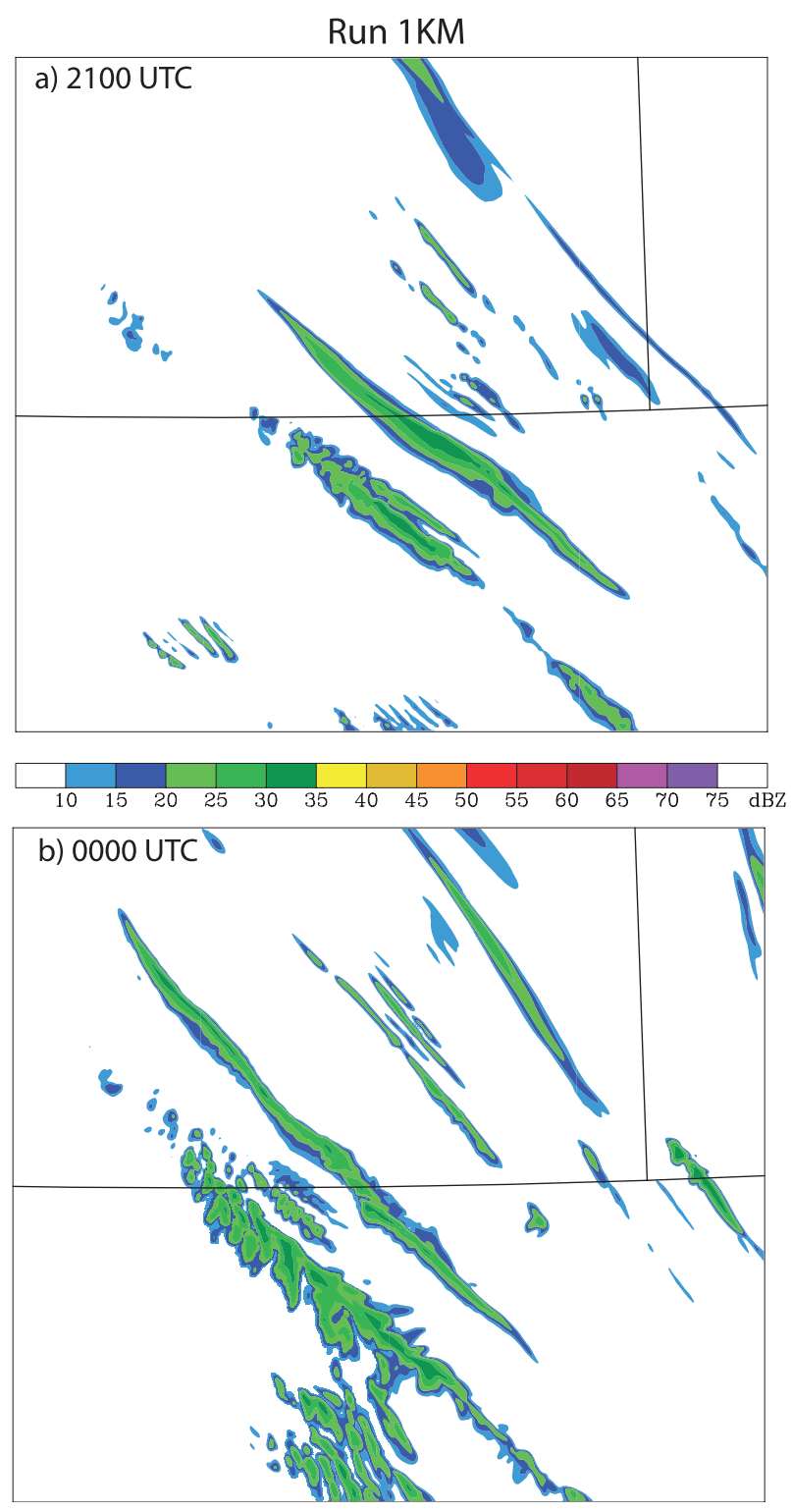

FIG. 20. Simulated composite radar reflectivity on domain 4 of run $1 \mathrm{KM}$ at (a) 2100 UTC 16 Feb and (b) 000017 Feb 2007.

16-17 February case (cf. Fig. 21 with Figs. 7 and 10), with a strong north-northwesterly upper-tropospheric jet (not shown) and an associated midlevel jet streak just east of the banded convection (Figs. 21b, 21e, and 21h). In all of these cases, negative potential vorticity was present at the location of the bands (according to the RUC analyses), and negative absolute vorticity was present either at or very near the band location. None of these bands occurred in regions with mesoscale saturation; however, MUCAPE was present in the RUC analyses either at or near the location where the bands developed (not shown).

Other instances of banded convection in environments with conditional, symmetric, and inertial instabilities have been documented in the literature, but rarely. Schultz and Knox (2007, their section 7) noted only the studies by Jascourt et al. (1988), Knox and Hoggatt (1996), and Schultz and Knox (2007) over the course of three decades. On the other hand, the event on 16-17 February 2007 frequently resembles other comparable events. Consequently, convective snowbands downwind of the Rocky Mountains in the presence of conditional, dry symmetric, and inertial instabilities seem to be common; indeed, at least three events in $3 \mathrm{yr}$ were observed without performing a formal climatology of such bands. Davis (1997) also showed a case of banded snowfall near the Front Range under similar synoptic and mesoscale conditions. Thus, this synoptic pattern appears to be favorable for snowbands in the lee of the Rocky Mountains. Despite this favorable environment (anticyclonic-shear side of a strong midlevel jet) for the release of multiple instabilities, and for the development of vorticity banners, how often banded convection develops in such environments is as yet unknown.

\section{b. Comparison to other conceptual models of precipitation bands}

We compare the results of these studies to two other types of banding that have been described in the literature. The first is that of banding in the comma heads of extratropical cyclones in the northeast U.S. cyclones documented by Novak et al. (2004, 2006, 2008, 2009). The banding in these events occurs in a region of largescale saturation, where conditional instability, moist symmetric instability, and inertial instability may also be present (Novak et al. 2010). In fact, about $30 \%$ of banded cases possessed conditional instability before the band formed. Whereas the stronger banded cases in Novak et al. (2010) occur in large-scale saturated air in the comma head, the weaker bands discussed in this article occur in large-scale subsaturation.

The second is that of banding over or downstream of mountains documented by Cosma et al. (2002), Kirshbaum and Durran (2005a,b), and Kirshbaum et al. (2007a,b). These studies show that banding occurs when dry circulations initiated by upstream topography in a conditionally unstable environment produce banded convection. Whereas Kirshbaum et al. (2007a) use an initial sounding that is nearly saturated at all levels, the environment in our event is initially unsaturated at all levels. In addition, Cosma et al. (2002) and Kirshbaum et al. (2007a) examine primarily upslope flow conditions, whereas strong downslope flow occurs in our event. Also, the environment of the bands for the studies by Cosma et al. (2002) and Kirshbaum et al. (2007a) is characterized only by conditional instability, not by moist symmetric, dry symmetric, or inertial instabilities, 

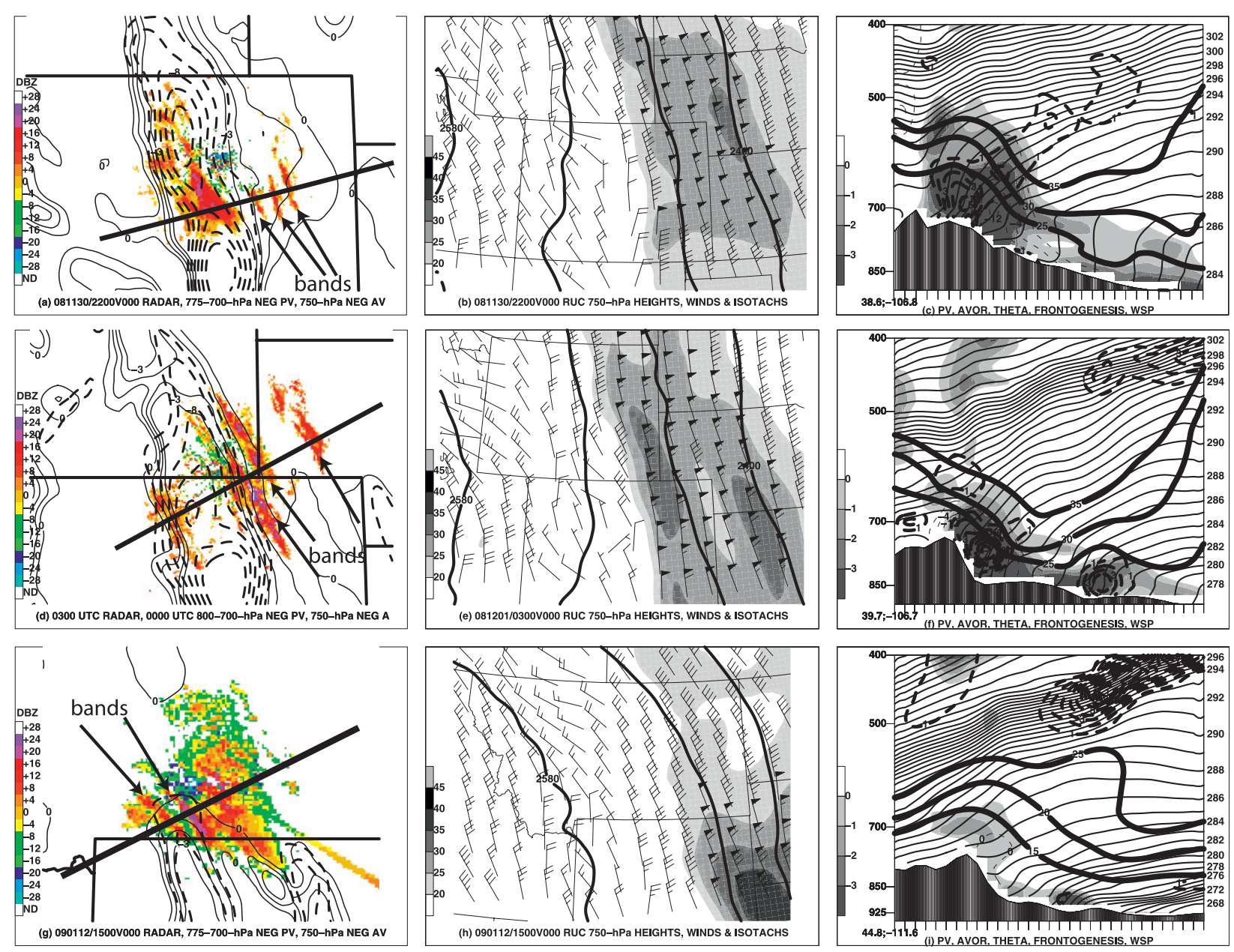

FIG. 21. Comparison between three periods of banded convective snowfall in the western United States: (a)-(c) 2200 UTC 30 Nov 2008 , (d)-(f) 0300 UTC 1 Dec 2008, and (g)-(i) 1500 UTC 12 Jan 2009. Shown in (a),(d), and (g) are the radar reflectivities from the nearest WSR-88D, the RUC analysis of potential vorticity in the 775-700-hPa layer (solid contours; negative values contoured every 1 PVU), and 750-hPa absolute vorticity (thick solid contours; negative values contoured every $4 \times 10^{-5} \mathrm{~s}^{-1}$ ). Shown in (b), (e), and (h) are the 750-hPa geopotential height ( $\mathrm{m}$, thick contours), winds (short barb represents $2.5 \mathrm{~m} \mathrm{~s}^{-1}$, long barb represents $5 \mathrm{~m} \mathrm{~s}{ }^{-1}$, pennant represents $25 \mathrm{~m} \mathrm{~s}^{-1}$ ), and isotachs ( $\mathrm{m} \mathrm{s}^{-1}$, shaded). Shown in (c),(f), and (i) are vertical sections along the lines shown in the corresponding panel in the left column, with the westernmost point along these lines on the left. Shown are potential temperature (thin solid contours every $2 \mathrm{~K}$ ), potential vorticity (negative values shaded in PVU), absolute vorticity (negative values contoured in thin dashed lines every $2 \times 10^{-5} \mathrm{~s}^{-1}$ ), positive frontogenesis [thick dashed lines every $1 \mathrm{~K}(100 \mathrm{~km})^{-1}(3 \mathrm{~h})^{-1}$ ], and wind speed (selected thick solid contours in $\mathrm{m} \mathrm{s}^{-1}$ to emphasize the locations of midlevel jets).

nor by the presence of frontogenetical forcing and other baroclinic effects. Thus, although the mountains appear to influence the production of circulations in both our case and that of Kirshbaum et al. (2007a), the cases differ in their stability. How the presence or absence of different instabilities affects the organization, maintenance, and longevity of the bands has not yet been addressed systematically.

\section{c. Comparison to other research on vorticity banners}

Several studies based on field observations from the Mesoscale Alpine Programme (MAP) confirmed the existence of PV banners over the Mediterranean Sea downstream of the Alps (e.g., Schär et al. 2003; Jiang et al. 2003; Grubišić 2004; Flamant et al. 2004). These banners sometimes had clouds associated with them (Jiang et al. 2003) but were apparently not associated with precipitation. In fact, Schär et al. (2003) suggested that these banners were primarily deformational, rather than convergent, and therefore were not likely to have strong vertical motions with them. The 16-17 February 2007 event, as well as the other similar events noted in section 4a and the case of Andretta and Geerts (2010), suggests that there may indeed be precipitation associated with 
some PV banners, when they exist in an environment that also includes frontogenetical forcing and conditional and symmetric instabilities.

\section{d. Numerical prediction of convective snowbands}

The major band that developed on 16-17 February 2007 produced several centimeters of snow that was generally unpredicted and led to adverse conditions, and thus understanding how to improve forecasts of such events is not merely an academic exercise. As was discussed in the introduction, the operational NAM model was unable to give any indication of banded convection in its forecast. Yet the NAM analyses at the same resolution showed most of the flow features, including vorticity banners downstream of topography, that are thought to have been important in this event. Furthermore, a model (WRF-ARW) using different model physics but the same initial conditions, and with explicitly predicted convection at higher resolution, was able to provide a greatly improved forecast of the observed bands. Even at similar resolution (9-km grid spacing), the WRF-ARW predicted some precipitation, though its structure was not completely realistic. It was shown in Fig. 8 that errors in the NAM's low- and midlevel temperature and moisture fields may have been partly to blame for the lack of precipitation in its forecast. A series of additional simulations on the 9-km grid were performed, testing the sensitivity to parameterizations of cumulus convection, boundary layer processes, and microphysics (not shown). Although there were differences in the specific locations and amounts of precipitation among these runs, they were all generally similar to one another and to run $9 \mathrm{KM}$ (Fig. 12a), and all represented an improvement on the NAM forecast. Although a systematic examination of the differences between these forecasts is beyond the scope of this study, further investigation of this and other similar cases may yield clues for how to improve forecasts of precipitation from banded convection.

\section{Conclusions}

A case with quasi-stationary banded convection producing heavy snow downstream of the Front Range of the Rocky Mountains was investigated through an examination of the observations and convection-permitting numerical simulations. Neither operational weather forecast models nor human forecasters predicted this event. A WRF-ARW simulation with different model physics but the same initial conditions as the model that failed to produce the bands in real time (the NAM) provided a greatly improved forecast of the banded snowfall.

The precipitation bands developed on the anticyclonic side of a midlevel jet streak, in a region with conditional instability (as indicated by positive CAPE), negative potential vorticity (i.e., dry symmetric instability), and negative absolute vorticity (i.e., inertial instability). Nearsurface frontogenesis along an equatorward-moving surface cold front, as well as an elevated frontogenesis maximum, provided the ascent for the major convective band. The minor bands were formed within weaker frontogenesis along nearly vertical isentropes that had an upslope component of motion. Numerical simulations showed that the individual convective bands formed in the presence of CAPE on the anticyclonic-shear edge of regions containing inertial instability, dry symmetric instability, or both. These regions of negative absolute and potential vorticity appeared to be similar to previously documented PV banners that originated from elevated terrain upstream. The convective circulations themselves then altered the vorticity field as well, causing narrow regions of inertial instability aloft. Two other similar events over the western United States provide evidence that similar synoptic patterns may underlie these types of banded convection.

The unusual and unpredicted banded convection in this case, and its relationship to the other similar cases discussed in this paper, provides motivation for further study of snowbands near complex terrain and in conditionally, symmetrically, and inertially unstable environments. How the atmosphere responds when more than one of these instabilities are released and how their release may lead to the observed organization into bands both remain unknown. The effects of strong horizontal shear on convection has not been explored either. Furthermore, the role of terrain gradients in initiating and maintaining the convection, and the ways in which baroclinic zones interact with this terrain, have not been explored. Sensitivity simulations in which various terrain features are altered or removed to reveal their importance are under way and will be presented in a future manuscript. Additionally, idealized numerical experiments with conditionally, symmetrically, and inertially unstable initial conditions (e.g., Blanchard et al. 1998), and in which topography is included, may lead us closer to understanding these complex phenomena.

Acknowledgments. We thank Dan Kirshbaum of Reading University for his assistance in interpreting this event within the context of his prior research, and Craig Epifanio of Texas A\&M University for helpful discussions regarding flows around topography. We also thank David Novak and two anonymous reviewers for their helpful and constructive suggestions that led to an improved manuscript. Model analyses and forecasts, WSR88D data, satellite imagery, and National Weather Service text products were obtained from the National 
Climatic Data Center. WSI NOWrad data and stage IV precipitation data were obtained from, and computing resources were provided by, the National Center for Atmospheric Research. RSS thanks Richard Johnson of Colorado State University for his support during this project. Partial support for RSS came from National Science Foundation Grant ATM-0500061 (R. Johnson), and partial support for DMS came from Vaisala Oyj and Grant 126853 from the Academy of Finland.

\section{REFERENCES}

Andretta, T. A., and B. Geerts, 2010: Heavy snowfall produced by topographically induced winds in the Snake River Plain of eastern Idaho: Part I-Observational analysis. Electron. J. Severe Storms Meteor., 5 (3). [Available online at http:// www.ejssm.org/ojs/index.php/ejssm/article/view/56/56.]

Benjamin, S. G., and Coauthors, 2004: An hourly assimilationforecast cycle: The RUC. Mon. Wea. Rev., 132, 495-518.

Bennetts, D. A., and B. J. Hoskins, 1979: Conditional symmetric instability-A possible explanation for frontal rainbands. Quart. J. Roy. Meteor. Soc., 105, 945-962.

Blanchard, D. O., W. R. Cotton, and J. M. Brown, 1998: Mesoscale circulation growth under conditions of weak inertial instability. Mon. Wea. Rev., 126, 118-140.

Bryan, G. H., J. C. Wyngaard, and J. M. Fritsch, 2003: Resolution requirements for the simulation of deep moist convection. Mon. Wea. Rev., 131, 2394-2416.

Chagnon, J. M., and S. L. Gray, 2009: Horizontal potential vorticity dipoles on the convective storm scale. Quart. J. Roy. Meteor. Soc., 135, 1392-1408.

Cosma, S., E. Richard, and F. Miniscloux, 2002: The role of smallscale orographic features in the spatial distribution of precipitation. Quart. J. Roy. Meteor. Soc., 128, 75-92.

Davis, C. A., 1997: Mesoscale anticyclonic circulations in the lee of the central Rocky Mountains. Mon. Wea. Rev., 125, 2838-2855.

Dudhia, J., 1989: Numerical study of convection observed during the Winter Monsoon Experiment using a mesoscale twodimensional model. J. Atmos. Sci., 46, 3077-3107.

Emanuel, K. A., 1983a: On assessing local conditional symmetric instability from atmospheric soundings. Mon. Wea. Rev., 111, 2016-2033.

_ 1983b: The Lagrangian parcel dynamics of moist symmetric stability. J. Atmos. Sci., 40, 2368-2376.

Flamant, C., E. Richard, C. Schär, R. Rotunno, L. Nance, M. Sprenger, and R. Benoit, 2004: The wake south of the Alps: Dynamics and structure of the lee-side flow and secondary potential vorticity banners. Quart. J. Roy. Meteor. Soc., 130, 1275-1303.

Grubišić, V., 2004: Bora-driven potential vorticity banners over the Adriatic. Quart. J. Roy. Meteor. Soc., 130, 2571-2603.

Holt, M. W., and A. J. Thorpe, 1991: Localized forcing of slantwise motion at fronts. Quart. J. Roy. Meteor. Soc., 117, 943-963.

Holton, J. R., 2004: An Introduction to Dynamic Meteorology. 4th ed. Academic Press, 535 pp.

Hoskins, B. J., 1974: The role of potential vorticity in symmetric stability and instability. Quart. J. Roy. Meteor. Soc., 100, 480-482.

Janjić, Z., 1994: The step-mountain eta coordinate model: Further developments of the convection, viscous sublayer, and turbulence closure schemes. Mon. Wea. Rev., 122, 927-945.
, R. Gall, and M. E. Pyle, cited 2010: Scientific documentation for the NMM solver. NCAR Tech. Note NCAR/TN477+STR, 54 pp. [Available online at http://nldr.library.ucar. edu/collections/technotes/asset-000-000-000-845.pdf.]

Jascourt, S. D., S. S. Lindstrom, C. J. Seman, and D. D. Houghton, 1988: An observation of banded convective development in the presence of weak symmetric stability. Mon. Wea. Rev., 116, 175-191.

Jiang, Q., R. B. Smith, and J. Doyle, 2003: The nature of the mistral: Observations and modeling of two MAP events. Quart. J. Roy. Meteor. Soc., 129, 857-875.

Johns, R. H., and C. A. Doswell III, 1992: Severe local storms forecasting. Wea. Forecasting, 7, 588-612.

Kain, J. S., 2004: The Kain-Fritsch convective parameterization: An update. J. Appl. Meteor., 43, 170-181.

__ , and Coauthors, 2008: Some practical considerations regarding horizontal resolution in the first generation of operational convection-allowing NWP. Wea. Forecasting, 23, 931-952.

Kirshbaum, D. J., and D. R. Durran, 2005a: Atmospheric factors governing banded orographic convection. J. Atmos. Sci., 62, 3758-3774.

— orographic convection. J. Atmos. Sci., 62, 1463-1479.

- , G. H. Bryan, R. Rotunno, and D. R. Durran, 2007a: The triggering of orographic rainbands by small-scale topography. J. Atmos. Sci., 64, 1530-1549.

—, R. Rotunno, and G. H. Bryan, 2007b: The spacing of orographic rainbands triggered by small-scale topography. J. Atmos. Sci., 64, 4222-4245.

Knievel, J. C., G. H. Bryan, and J. P. Hacker, 2007: Explicit numerical diffusion in the WRF model. Mon. Wea. Rev., 135, 3803-3824.

Knox, J. A., 2003: Inertial instability. Encyclopedia of the Atmospheric Sciences, J. Holton, J. Pyle, and J. Curry, Eds., Academic Press, 1004-1013.

— , and B. D. Hoggatt, 1996: Mesoscale dynamics of mid-level convection in an intense mid-latitude anticyclone. Preprints, Seventh Conf. on Mesoscale Processes, Reading, United Kingdom, Amer. Meteor. Soc., 453-455.

Koch, S. E., M. desJardins, and P. J. Kocin, 1983: An interactive Barnes objective map analysis scheme for use with satellite and conventional data. J. Climate Appl. Meteor., 22, 1487-1503.

Lean, H. W., P. A. Clark, M. Dixon, N. M. Roberts, A. Fitch, R. Forbes, and C. Halliwell, 2008: Characteristics of highresolution versions of the Met Office Unified Model for forecasting convection over the United Kingdom. Mon. Wea. Rev., 136, 3408-3424.

Lin, Y., and K. E. Mitchell, 2005: The NCEP stage II/IV hourly precipitation analyses: Development and applications. Preprints, 19th Conf. on Hydrology, San Diego, CA, Amer. Meteor. Soc., 1.2. [Available online at http://ams.confex.com/ams/ pdfpapers/83847.pdf.]

Novak, D. R., L. F. Bosart, D. Keyser, and J. S. Waldstreicher, 2004: An observational study of cold season banded precipitation in northeast U.S. cyclones. Wea. Forecasting, 19, 993-1010.

— J. S. Waldstreicher, D. Keyser, and L. F. Bosart, 2006: A forecast strategy for anticipating cold season mesoscale band formation within eastern U.S. cyclones. Wea. Forecasting, 21, 3-23.

, B. A. Colle, and S. E. Yuter, 2008: High-resolution observations and model simulations of the life cycle of an intense 
mesoscale snowband over the northeastern United States. Mon. Wea. Rev., 136, 1433-1456.

_ _ _ , and R. McTaggart-Cowan, 2009: The role of moist processes in the formation and evolution of mesoscale snowbands within the comma head of northeast U.S. cyclones. Mon. Wea. Rev., 137, 2662-2686.

- — _ , and A. R. Aiyyer, 2010: Evolution of mesoscale precipitation band environments within the comma head of northeast U.S. cyclones. Mon. Wea. Rev., 138, 2354-2374.

Parsons, D. B., and P. V. Hobbs, 1983: The mesoscale and microscale structure and organization of clouds and precipitation in midlatitude cyclones. XI: Comparisons between observational and theoretical aspects of rainbands. J. Atmos. Sci., 40, $2377-$ 2398.

Raymond, D. J., and H. Jiang, 1990: A theory for long-lived mesoscale convective systems. J. Atmos. Sci., 47, 3067-3077.

Roebber, P. J., D. M. Schultz, B. A. Colle, and D. J. Stensrud, 2004: Toward improved prediction: High-resolution and ensemble modeling systems in operations. Wea. Forecasting, 19, 936-949.

Rotunno, R., V. Grubišić, and P. K. Smolarkiewicz, 1999: Vorticity and potential vorticity in mountain wakes. J. Atmos. Sci., 56, 2796-2810.

Schär, C., M. Sprenger, D. Lüthi, Q. Jiang, R. B. Smith, and R. Benoit, 2003: Structure and dynamics of an Alpine potentialvorticity banner. Quart. J. Roy. Meteor. Soc., 129, 825-855.

Schultz, D. M., and J. A. Knox, 2007: Banded convection caused by frontogenesis in a conditionally, symmetrically, and inertially unstable environment. Mon. Wea. Rev., 135, 2095-2110.

- and P. N. Schumacher, 1999: The use and misuse of conditional symmetric instability. Mon. Wea. Rev., 127, 2709-2732; Corrigendum, 128, 1573.
, D. S. Arndt, D. J. Stensrud, and J. W. Hanna, 2004: Snowbands during the cold-air outbreak of 23 January 2003. Mon. Wea. Rev., 132, 827-842.

Schwartz, C. S., and Coauthors, 2009: Next-day convectionallowing WRF model guidance: A second look at 2-km versus 4-km grid spacing. Mon. Wea. Rev., 137, 3351-3372.

Skamarock, W. C., and Coauthors, cited 2008: A description of the Advanced Research WRF version 3. NCAR Tech. Note NCAR/TN-475+STR, 113 pp. [Available online at http:// www.mmm.ucar.edu/wrf/users/docs/arw_v3.pdf.]

Thompson, G., P. R. Field, R. M. Rasmussen, and W. D. Hall, 2008: Explicit forecasts of winter precipitation using an improved bulk microphysics scheme. Part II: Implementation of a new snow parameterization. Mon. Wea. Rev., 136, 5095-5115.

Thorpe, A. J., and K. A. Emanuel, 1985: Frontogenesis in the presence of small stability to slantwise convection. J. Atmos. Sci., 42, 1809-1824.

Uccellini, L. W., and S. E. Koch, 1987: The synoptic setting and possible energy sources for mesoscale wave disturbances. Mon. Wea. Rev., 115, 721-729.

Weckwerth, T. M., J. W. Wilson, R. M. Wakimoto, and N. A. Crook, 1997: Horizontal convective rolls: Determining the environmental conditions supporting their existence and characteristics. Mon. Wea. Rev., 125, 505-526.

Weisman, M. L., C. Davis, W. Wang, K. W. Manning, and J. B. Klemp, 2008: Experiences with 0-36-h explicit convective forecasts with the WRF-ARW model. Wea. Forecasting, 23, 407-437.

Xu, Q., 1992: Formation and evolution of frontal rainbands and geostrophic potential vorticity anomalies. J. Atmos. Sci., 49, 629-648. 